\title{
Global representation of tropical cyclone-induced short-term ocean thermal changes using Argo data
}

\author{
L. Cheng ${ }^{1}$, J. Zhu ${ }^{1}$, and R. L. Sriver ${ }^{2}$ \\ ${ }^{1}$ International Center for Climate and Environment Sciences, Institute of Atmospheric Physics, \\ Chinese Academy of Sciences, Beijing, China \\ ${ }^{2}$ Department of Atmospheric Sciences, University of Illinois, Urbana-Champaign, IL, USA
}

Correspondence to: J. Zhu (jzhu@ mail.iap.ac.cn)

Received: 30 October 2014 - Published in Ocean Sci. Discuss.: 9 December 2014

Revised: 20 August 2015 - Accepted: 31 August 2015 - Published: 18 September 2015

\begin{abstract}
Argo floats are used to examine tropical cyclone (TC) induced ocean thermal changes on the global scale by comparing temperature profiles before and after TC passage. We present a footprint method that analyzes cross-track thermal responses along all storm tracks during the period 2004-2012. We combine the results into composite representations of the vertical structure of the average thermal response for two different categories: tropical storms/tropical depressions (TS/TD) and hurricanes. The two footprint composites are functions of three variables: cross-track distance, water depth and time relative to TC passage. We find that this footprint strategy captures the major features of the upperocean thermal response to TCs on timescales up to 20 days when compared against previous case study results using in situ measurements. On the global scale, TCs are responsible for $1.87 \mathrm{PW}\left(11.05 \mathrm{~W} \mathrm{~m}^{-2}\right)$ of heat transfer annually from the global ocean to the atmosphere during storm passage (03 days). Of this total, $1.05 \pm 0.20 \mathrm{PW}\left(4.80 \pm 0.85 \mathrm{~W} \mathrm{~m}^{-2}\right)$ is caused by TS/TD and $0.82 \pm 0.21 \mathrm{PW}\left(6.25 \pm 1.5 \mathrm{~W} \mathrm{~m}^{-2}\right)$ is caused by hurricanes. Our findings indicate that ocean heat loss by TCs may be a substantial missing piece of the global ocean heat budget. Changes in ocean heat content (OHC) after storm passage are estimated by analyzing the temperature anomalies during wake recovery following storm events (4-20 days after storm passage) relative to pre-storm conditions. Results indicate the global ocean experiences a $0.75 \pm 0.25 \mathrm{PW}\left(5.98 \pm 2.1 \mathrm{~W} \mathrm{~m}^{-2}\right)$ heat gain annually for hurricanes. In contrast, under TS/TD conditions, the ocean experiences $0.41 \pm 0.21 \mathrm{PW}\left(1.90 \pm 0.96 \mathrm{~W} \mathrm{~m}^{-2}\right)$ ocean heat loss, suggesting the overall oceanic thermal response is particularly sensitive to the intensity of the event. The ocean heat
\end{abstract}

uptake caused by all storms during the restorative stage is $0.34 \mathrm{PW}$.

\section{Introduction}

Tropical cyclones (TCs) provide an effective mechanism to transport heat, mass and nutrients in the ocean, while also exchanging enthalpy with the atmosphere. Multiple lines of evidence from previous observational and modeling studies indicate that these relatively small-scale and transient events can influence large-scale dynamical processes in both the ocean (Emanuel, 2001; Sriver and Huber, 2007) and the atmosphere (Camargo and Sobel, 2005; Hart, 2011; Jansen et al., 2010; Sriver and Huber, 2010)

TCs affect ocean processes and properties on multiple spatial and temporal scales. On scales relevant for climate dynamics, the cumulative effects of TCs on the ocean have been shown to be important for controlling tropical and subtropical ocean temperature patterns through enhanced subsurface mixing (Fedorov et al., 2010; Sriver et al., 2010). It has been hypothesized that increases in this mixing associated with more TC activity are capable of sustaining climates with permanent El Niño-like temperature patterns such as during the early Pliocene, $\sim 5$ million years ago (Fedorov et al., 2010). On inter-seasonal scales, TC-induced changes in ocean temperature can impact the atmospheric circulations through dynamical connections affecting mid-latitude weather in subsequent winters (Hart, 2011; Hart et al., 2007b). This mechanism, and in general the relatively strong thermal inertia of the ocean, implies a longer memory of tropical cyclones in 
the ocean than in the atmosphere. On synoptic scales, TCinduced cooling at the surface via enhanced mixing can limit TC intensification (e.g., Ginis, 2002).

Understanding the ocean's response to TCs on various spatial and temporal scales is an ongoing area of active research. Since the 1950s, ocean vessels, moorings, and aircraft have been observing ocean conditions in TC-affected regions, which has assisted in building the basic framework for understanding how the ocean responds to TC forcing (Black and Dickey, 2008; Price, 1981, 1983; Price et al., 1994; Shay and Elsberry, 1987; Shay et al., 1989). The response of the upper ocean to TC forcing is typically characterized by surface cooling in the storm wake and subsurface warming caused by a variety of oceanic and atmospheric processes, including generation of near-inertial internal oscillations, geostrophic advection, Ekman pumping, and surface fluxes. Previous studies analyzing the ocean response to TCs have generally been limited by the availability of observations and/or focus on a limited number of storms, resulting in storm-to-storm variations (Bell et al., 2012; Cione and Uhlhorn, 2003; Lin et al., 2009a, b). Until recently, these limitations in data coverage have prevented a global-scale perspective of how TCs affect the ocean.

Previous efforts to quantify the impact of TCs on upper ocean heat content $(\mathrm{OHC})$ have relied primarily on nearsurface observations (Sriver and Huber, 2007; Sriver et al., 2008; Jansen et al., 2010) and altimetry sea level data (Mei et al., 2013), inferring a redistribution of heat via vertical mixing. Because there is a relatively firm theoretical understanding of the ocean's response to TC wind forcing (Price, 1981), global sea-surface temperature (SST) fields from satellites and reanalysis serve as the basis for first-order estimates of TC impacts, because they offer global coverage and relatively high spatial and temporal resolution. But, these methods come along with fundamental assumptions about the interior ocean response. For example, Sriver and Huber (2007) assume that the upper $50 \mathrm{~m}$ depth ocean is cooled homogeneously within TC cold wakes, reflecting the temperature change observed at the surface, and all cooling is achieved through vertical mixing. Given these assumptions, they estimate that $0.2-0.4 \mathrm{PW}$ of heat is transported into the ocean interior globally. Using improved methodologies, several additional observational studies have generally supported this result (Jansen et al., 2010; Sriver et al., 2008; Mei et al., 2013).

A key uncertainty missing in the above studies is the effect of enthalpy exchange at the air-sea interface (Emanuel, 1991, 1999). Typically these fluxes are estimated by measuring the humidity near the sea surface using mooring instruments and calculating the latent heat flux according to a parameterized bulk equation. A so-called drag coefficient is needed to approximate the efficiency of heat transfer, which is one of the sources of uncertainties in the high-wind weather conditions (Powell et al., 2003). Another source of uncertainty arises due to the spatial and temporal variations in humidity, temperature and wind speed under highly chaotic wind conditions, since the winds undergo rapid changes in direction and magnitude in TC conditions (Wright et al., 2001). Additionally, the effect of sea spray must also be taken into account, since it represents an efficient mechanism transporting enthalpy in the air-sea boundary layer under strong winds. These uncertainties make the direct measurements of the airsea fluxes difficult, and thus it is perhaps necessary to accumulate large numbers of measurements to achieve statistically significant results. Despite these limitations, studies have shown that the air-sea heat fluxes within TCs are on the order of 2 to 3 times greater than the background heat fluxes in quiescent conditions (D'Asaro, 2003; Lin et al., 2009). These studies improve the understanding of the air-sea heat exchange by TCs, but global-scale estimates are difficult.

Following the surface drag methods, Trenberth and Fasullo (2007) use a high-resolution model to examine the TCinduced water and energy budgets on the global scale. Their estimate of heat flux is based on an empirical relationship between heat flux and wind speed (Trenberth et al., 2007). They find that $0.17 \mathrm{PW}$ heat is released from the ocean to the atmosphere within $400 \mathrm{~km}$ of the storm center, and $0.58 \mathrm{PW}$ within $1600 \mathrm{~km}$.

These previous studies suggest that TCs induce a substantial amount of heat exchange between the atmosphere, oceanic mixed layer, and upper thermocline; thus, these events may play an important role in influencing global heat budgets and climate. However, comprehensive global estimates of air-sea exchanges, ocean interior thermal changes, and net effects on OHC have not yet been estimated using global, vertically resolved ocean observations.

A key difficulty in quantifying the global distribution of TC-induced oceanic thermal response is the lack of allweather observations with sufficient horizontal, vertical and temporal coverage and resolution. Since the year 2000, Argo profiling floats have provided a global network of in situ ocean surface and subsurface observations (von Schuckmann and Le Traon, 2011; Willis et al., 2009). The profiles measure water temperature and salinity from the surface $(\sim 5 \mathrm{~m})$ to $\sim 2000 \mathrm{~m}$ depth, even under extreme weather conditions such as TCs. Since 2004, the Argo system has maintained a global array network with a resolution of about 3 by $3^{\circ}$ in space similar to the XBT-based system (Freeland et al., 2009). However, the main advantage of the Argo system over previous observational systems is that the floats are more evenly distributed in space and time over the ocean and can observe conditions from greater depths.

Several recent studies have used Argo data to examine ocean conditions under TCs (Lin et al., 2009b; Liu et al., 2007; Mei et al., 2013; Park et al., 2011). Liu et al. (2007) concentrated on northwestern Pacific typhoons, suggesting that TC signals (e.g., sea surface cooling) can be captured by Argo data and that these signals are statistically significant. Lin et al. (2009b) examined ocean responses under a specific TC (Nargis), showing a clear ocean thermal change 
from a series of Argo data near the storm. These results support the reliability of Argo observations in severe weather conditions. More recent work examining TC-induced ocean heat content changes in the western Pacific (Park et al., 2011) represents the first attempt to investigate systematically the TC-induced ocean thermal changes on a basin scale using Argo data. While the authors do identify a TC signature in the Argo data, the TC-induced subsurface temperature response is sensitive to the season in which TCs occur. Furthermore, the TC-induced effect is difficult to separate from the background variability, particularly for weak storms.

Here we present a new method to examine global TCocean interactions using Argo data that examines all storms globally and characterizes the global mean of the cross-track ocean response to TCs using a footprint method that follows along the storm tracks. We categorize the TC events into two separate groups: tropical storms/tropical depressions (TS/TD) and hurricanes. In addition, we separate the ocean's response into two stages: the forced stage (0-3 days relative to storm passage) and the recovery stage (4-20 days relative to storm passage). We use this technique to analyze TCinduced ocean thermal responses and latent heat fluxes on a global scale, accounting for regional variability in background ocean conditions. The paper is organized as follows. We describe the data and footprint methodology in Sect. 2. We present the results and discussion in Sect. 3. We discuss the caveats of the method in Sect. 4, and Sect. 5 outlines the main conclusions.

\section{Data and methods}

\subsection{Data}

Argo floats drift freely at a fixed pressure (usually $1000 \mathrm{~m}$ depth and occasionally at 1200 and $1500 \mathrm{~m}$ ) for about 910 days. After this period, the floats descend rapidly to a profiling pressure (usually $2000 \mathrm{~m}$ deep) and then rise, collecting near-instantaneous profiles of pressure, temperature, and salinity data on their way to the surface (within a span of about $2 \mathrm{~h}$ ). The floats remain at the surface for less than 1 day, transmitting the data collected via a satellite link back to a ground station and allowing the satellite to determine their surface positions. The floats then sink again to a parking depth of $\sim 1000 \mathrm{~m}$ and repeat the cycle.

Argo data are available on the website of the National Oceanographic Data Center/Global Argo Data Repository. In this study, we use Argo data from January 2004 to December 2012 (downloaded on October 2013). We discard all the profiles in the so-called grey list (Willis et al., 2009), within which the Argo floats with pressure drift error are listed. Both delayed mode (data available several months after passing careful quality control processes) and real-time mode (data available to users within a 2-day time frame) data are used where available, and Argo quality control flags are used to eliminate spurious measurements. We apply an addi- tional boundary check as follows. If a temperature anomaly within 200 to $1000 \mathrm{~m}$ from a pair (discussed in more detail in Sect. 2.2) is larger than $2^{\circ} \mathrm{C}$ (or smaller than $-2^{\circ} \mathrm{C}$ ), the anomaly is labeled "spurious". If there are more than five "spurious" labels from a single pair, the pair is rejected and all of the "spurious" anomalies are removed. This is a widely used quality control process and helps to get rid of the spikes and anomalous profiles.

Tropical cyclone information comes from the NOAA's Tropical Prediction Center "best track" data set (http:// weather.unisys.com/). The data set contains 6-hourly records of maximum wind speeds, pressure and location. We collect all TC tracks globally between January 2004 and December 2012, totaling 885 events.

\subsection{Composite footprint method}

We introduce a footprint method that averages all of the TCinduced cross-track (i.e., perpendicular to the storm's direction of motion) ocean temperature changes. Argo pairs are selected to compare temperature profiles before and after storm passage according to the following criteria.

1. The pre-storm Argo profile is within -12 to -2 days before storm passage and the post-storm Argo profile is within 0 to 20 days after storm passage. The 20day limit is selected because SST changes are largely restored to pre-storm conditions within 20 days after storm passage. Furthermore, it is increasingly difficult to separate TC effects from the seasonal cycle of SST on timescales longer than 20 days. Data within -2 to 0 days prior to storm passage are not used as pre-storm reference profiles, since they may be affected by TC processes (e.g., increased heat fluxes ahead of storms) and horizontal advection (Huang et al., 2009).

2. The locations of the pre-storm and post-storm Argo profiles are within $0.2^{\circ}$ of each other. Ideally, this comparison should be made at the same location, but it is not possible due to the heterogeneity of the observing system (both in space and time). Therefore, $0.2^{\circ}$ is selected as the maximum horizontal distance between the reference and TC-affected Argo floats, since we believe it can both minimize the influences of the background signals (such as meso-scale eddies, boundary currents, and waves) and maximize the size of our TC-affected pairs' data set. Sensitivity analysis shows that the background ocean variability (not due directly to TC effects) within $0.2^{\circ}$ can be neglected when averaging over a large data set. However, background variability can contaminate the TC signal for larger horizontal constraints (e.g., $0.5^{\circ}$ ). Furthermore, horizontal velocities within western boundary ocean currents (e.g., the Gulf Stream) and geostrophic vortices within TC regions are typically on the order of $\mathrm{O}(10-100) \mathrm{cm} \mathrm{s}^{-1}$ (Shay et al., 1998). These currents can effectively transport a float 
more than $0.2^{\circ}$ away from its original position on the timescales of our TC analysis. Thus, the maximum $0.2^{\circ}$ spatial constraint largely filters these floats from our results, so that we do not contaminate the TC analysis with transient effects of larger-scale dynamics.

3. All of the Argo pairs are within $8^{\circ}$ relative to the center of the storm track, perpendicular to the storm's direction of translation. Thus, $16^{\circ}$ is assumed to be the maximum cross-track scale of the area affected by TCs. This constraint is a first-order assumption, and we will analyze the horizontal scale of the globally averaged TC response extensively in the results section. Additional information about the composite footprint method can be found in Appendix A.

The footprint method outlined above features several key methodological limitations, which include (i) neglecting along-track TC-induced ocean variability; (ii) lack of Argo float comparisons within individual storms due to poor sampling at these spatial and temporal scales; and (iii) the effect of background ocean variability at specific sampled locations, which is difficult due to the sparseness of the floats and the frequency of the measurements. A sensitivity test on the effect of background variability is presented in Appendix B, indicating that there is no significant systematic bias induced by background variability when using the footprint method.

\subsection{Estimation of ocean heat content changes during 0-3 days after storm passage}

Since the air-sea exchanges in the TC affected regions within 0-3 days of the storm passage are dominated by TC effects, which are several times larger than the background air-sea heat exchanges, it is reasonable to assume that the net ocean heat change within the TC-affected regions during this period is totally induced by TCs. Our choice of 3 days is to, at least partially, average out any float drift caused by inertial oscillations. This strategy is based on the notion that the ocean must be the energy source of a storm, so the total heat loss in the ocean during the storm is transported to the air as air-sea heat flux during the storm passage ( $0-3$ days). The averaged $\mathrm{OHC}$ change is calculated as follows (in Watts):

$$
\begin{aligned}
\mathrm{QA}_{\mathrm{TSTD}}= & L_{\text {track-TSTD }}\left[\int_{\text {dist }=-8}^{\mathrm{dist}=8} \frac{1}{T_{3 \text { days }}} \int_{\delta t=0}^{\delta t=3 \text { depth }=1200} \int_{\text {depth }=0}\right. \\
& \left.\rho c_{\mathrm{p}} F_{\mathrm{TSTD}}(\mathrm{dist} \text {, depth, } \delta t) d_{\mathrm{depth}} d_{\delta t} d_{\mathrm{dist}}\right] / T_{\text {year }}, \\
\mathrm{QA}_{\text {Hur }}= & L_{\text {track-Hur }}\left[\int_{\text {dist }=-8}^{\mathrm{dist}=8} \frac{1}{T_{3} \text { days }} \int_{\delta t=0}^{\delta t=3 \text { depth }=1200} \int_{\text {depth }=0}^{1}=0\right. \\
& \left.\rho c_{\mathrm{p}} F_{\text {Hur }}(\text { dist, depth, } \delta t) d_{\text {depth }} d_{\delta t} d_{\text {dist }}\right] / T_{\text {year }},
\end{aligned}
$$

where $c_{\mathrm{p}}$ is heat capacity of seawater $\sim 4186 \mathrm{~J} \mathrm{~kg}^{-1}{ }^{\circ} \mathrm{C} ; \rho$ is density of seawater, which is calculated using Argo salinity, pressure and temperature measurements before the storm;
$T_{\text {year }}$ is the duration of one calendar year in seconds, to calculate an annual mean; and $L_{\text {track-TSTD }}$ and $L_{\text {track-Hur }}$ are averaged track length within 1 year, about $1.4 \times 10^{8} \mathrm{~m}$ and $8.3 \times 10^{7} \mathrm{~m}$ for TS/TD and hurricanes, respectively, which are obtained by averaging the track length from 2004 to 2012.

We choose the time period between 0 and 3 days, because it likely captures the majority of the air-sea heat exchange during storm passage. However, other mechanisms may also influence air-sea heat flux in this time period, such as storm-induced cooling via mixing and wave generation. TC-induced surface cooling can cause a reversal of surface fluxes in the days following storm passage, which marks the transition between the forcing stage and the recovery stage. Some studies suggest fluxes may reverse sign around 2 days after TC passage (Dare and McBride, 2011; Lloyd and Vecchi, 2011). The exact timing of this reversal depends on many factors, such as storm intensity, translation speed and regional conditions, and the best choice is unclear in a global context. We performed sensitivity tests of the TC response to different choices of the time length $(0-2,0-2.5,0-3.5$ and $0-4$ days), and the results (not shown) and interpretations are generally consistent for all timescales.

\subsection{Estimation of air-sea fluxes during TC passage}

We examine the air-sea heat transfer rate in the TC-affected regions by averaging air-sea heat flux as follows (in $\mathrm{W} \mathrm{m}^{-2}$ ):

$H_{\mathrm{TSTD}}=\mathrm{QA}_{\mathrm{TSTD}} /\left(L_{\text {track}-\mathrm{TSTD}} \times R\right)$,
$H_{\mathrm{Hur}}=\mathrm{QA}_{\mathrm{Hur}} /\left(L_{\text {track}-\mathrm{Hur}} \times R\right)$,

where $R$ is the cross-track size of the TC-affected region that is set to be $16^{\circ}$ ( $\pm 8^{\circ}$ across the track). The other variables are consistent with $\mathrm{QA}$ TSTD and $\mathrm{QA}_{\mathrm{Hur}}$.

\subsection{Estimation of ocean heat content changes during 4-20 days after storm passage}

We estimate the $\mathrm{OHC}$ changes during the restorative stage by examining the average temperature response between 4 and 20 days after storm passage, referenced to pre-storm conditions. We choose 20 days as the maximum duration, because it is difficult to separate TC effects from seasonal signals on timescales greater than 3 weeks. Sensitivity tests for the different choices of the time length are also conducted (4-18, 4-19 and 4-21 days). The results of these tests (not shown) suggest the magnitude of the TC signal is relatively insensitive to the choice of timescales for the time periods considered. 


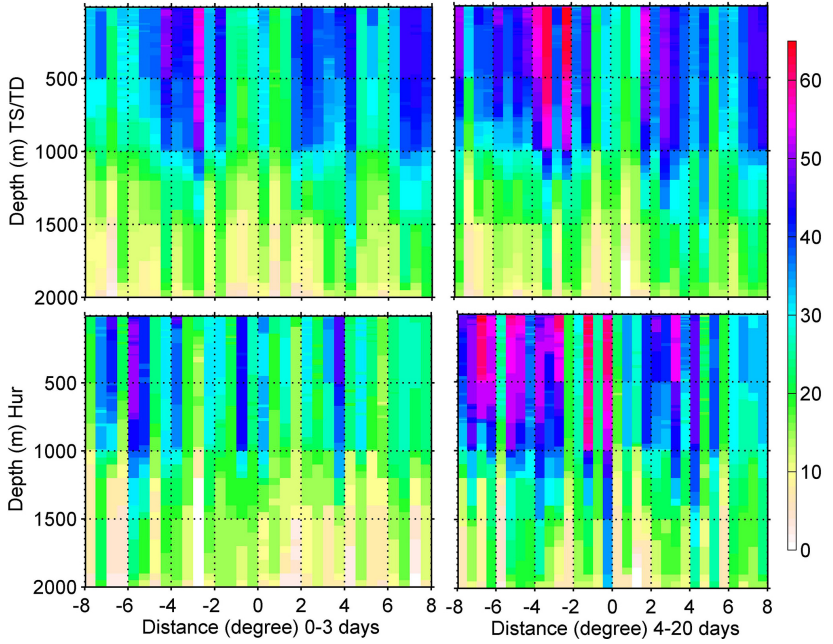

Figure 1. Count of TC-affected pairs in each $0.5^{\circ}$ distance bin from $-8^{\circ}$ to $8^{\circ}$ across the storm track for two footprint composites: TS/TD in the upper panel, hurricanes in the bottom panel. The statistics are conducted in two time periods: 0-3 days on the left, 4-20 days on the right.

We calculate $\mathrm{OHC}$ changes using (in Watts)

$$
\begin{aligned}
\mathrm{QN}_{\mathrm{TSTD}}= & L_{\text {track-TSTD }}\left[\int_{\text {dist }=-8}^{\text {dist }=8} \frac{1}{T_{17 \text { days }}} \int_{\delta t=4}^{\delta t=20 \text { depth }=1200} \int_{\text {depth }=0}^{1200}\right. \\
& \left.\rho c_{\mathrm{p}} F_{\mathrm{TSTD}}(\mathrm{dist}, \text { depth, } \delta t) d_{\mathrm{depth}} d_{\delta t} d_{\mathrm{dist}}\right] / T_{\text {year }},
\end{aligned}
$$

$$
\begin{aligned}
\mathrm{QN}_{\text {Hur }}= & L_{\text {track-Hur }}\left[\int_{\text {dist }=-8}^{\mathrm{dist}=8} \frac{1}{T_{17 \text { days }}} \int_{\delta t=4}^{\delta t=20 \mathrm{depth}=1200} \int_{\text {depth }=0}\right. \\
& \left.\rho c_{\mathrm{p}} F_{\text {Hur }}(\text { dist, depth, } \delta t) d_{\mathrm{depth}} d_{\delta t} d_{\text {dist }}\right] / T_{\text {year }},
\end{aligned}
$$

where $T_{17}$ days is the duration of 17 days in seconds. The other variables are the same as those in calculating $\mathrm{QA}_{\mathrm{TSTD}}$ and $\mathrm{QA}_{\mathrm{Hur}}$.

Limitations of this methodology include the following.

1. The $\mathrm{OHC}$ changes induced by TCs are averaged within 4 to 20 days after storm passage, which approximately represents the restoration stage. However, the ocean changes may not be fully restored during this time interval. As noted previously, we choose this time period because TC signals are difficult to separate from the background seasonal cycle on longer timescales.

2. The internal waves generated by TCs induce fluctuations in temperature, which could potentially bias our results. However, we hypothesize that these wave effects average to zero because we are using a large number of Argo pairs $(\sim 4410)$.

\section{Results and discussion}

Here we present the three-dimensional footprint maps for two time intervals, $0-3$ and 4-20 days referenced to storm passage. The 0-3-day interval represents about two inertial periods and reflects the direct ocean response to storm forcing (Sanford et al., 2011). We choose 3 days as an upper limit to the forced stage based on the following methodological constraints, limitations and uncertainties: (1) TC track information is every 6-12 h, and Argo data may be offset by several hours due to their ascent speed; together these effects can lead to observational offsets of up to 1 day; and (2) the inertial period changes rapidly with latitude in TC-affected regions (from 1 to 3 days). Considering these uncertainties, we choose 3 days as an approximation of the forced stage on the global scale, which represents the initial period of the TCs' influence on upper-ocean properties. We have conducted additional sensitivity tests to the choice of forced stage time interval using -1 to 2 days relative to storm passage, and the results are generally consistent with the results presented here.

After 4 days, the ocean typically begins recovering to prestorm and/or climatological conditions. While this restoration period can persist from weeks to months (Mei et al., 2013; Mei and Pasquero, 2013), this analysis averages the thermal response between 4 and 20 days after storm passage to estimate the mean ocean response during the recovery stage. Anomalies for both forced and recovery stages are referenced to pre-storm conditions as discussed in the methods section.

The amount of data for each footprint composite for the two time periods is shown in Fig. 1. In the upper $100 \mathrm{~m}$, the number of measurements is generally more than 30 in each $0.5^{\circ}$ box, except near the storm center. The measurements generally decrease with depth, especially deeper than 1000 , 1200 and $1500 \mathrm{~m}$ (parking depths).

\subsection{The 0-3-day footprint of ocean thermal changes}

During storm passage, in the so-called forcing stage (Price et al., 1994), the cyclonic winds generally pump cold water up to the surface near the storm eye (Ekman pumping) and generate divergent currents in the upper ocean. To compensate for the upwelling, downwelling away from the track occurs over a large area, appearing as ocean warming in the subsurface regions. Meanwhile, the strong and sudden disturbance of storm winds generates near-inertial horizontal currents (Shay and Elsberry, 1987) whose vertical shear leads to cold-water entrainment at the base of the mixed layer.

The detailed vertical structure of interior ocean responses to hurricanes and TS/TD are presented in Fig. 2a, c, where the significant signals are isolated compared with background variations. The standard errors are shown in Fig. 2b, d. Figure 2 shows that both hurricanes and TS/TD induce an asymmetric sea surface cooling with pronounced cooling 

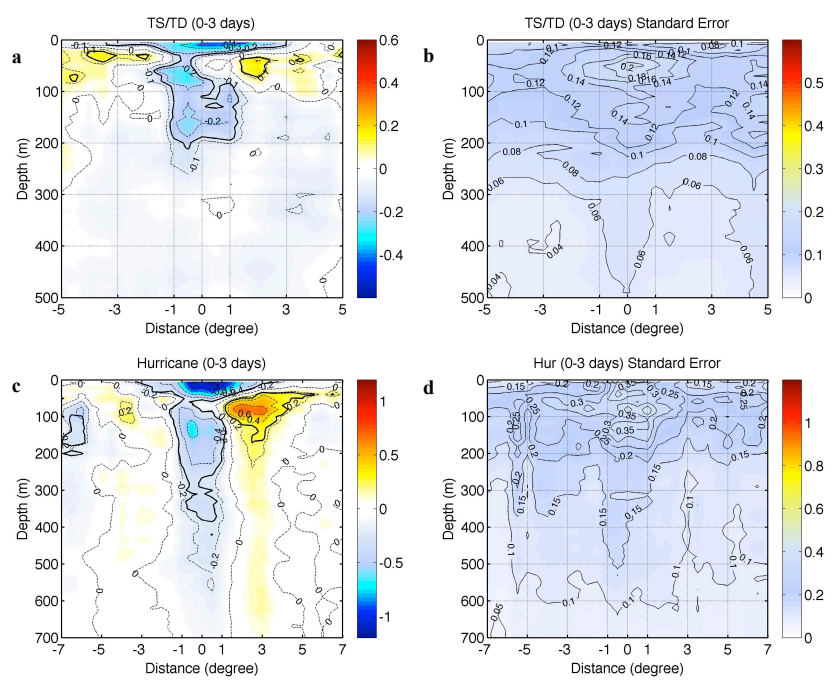

Figure 2. The 0-3-day averaged thermal changes (relative to prestorm conditions) as a function of depth and distance, in TC track coordinates. (a) TS/TD, between +5 and $-5^{\circ}$ from the track center; the dashed contour interval is $0.1^{\circ} \mathrm{C}$, and the solid black contours isolate the $90 \%$ confidence interval of the signals. The standard error of the footprint is presented in (b). (c) is the 0-3-day footprint for hurricanes, between $\pm 7^{\circ}$ from the track center, the dashed contour interval is $0.2^{\circ} \mathrm{C}$, and the solid black contours isolate the $90 \%$ confidence interval of the signals. The standard error of the footprint is presented in (d). The unit is ${ }^{\circ} \mathrm{C}$.

on the right side of the track (in track coordinates). A much weaker pattern is found on the opposite side, supporting the asymmetry of the ocean response documented previously in the literature. These near-surface cooling signals have uncertainties (standard errors in Fig. 2b, d) with magnitudes of less than $40 \%$ of the signals. The rightward-biased cooling in the track coordinate system near the surface is also found in previous studies (left side in the Southern Hemisphere) (Dare and McBride, 2011; Price, 1981, 1983; Sanford et al., 2011; Dickey et al., 1998) due to the stronger vertical shear in the right side of the track. This mechanism contributes $\sim 80 \%$ of the SST response (Price et al., 1994). Another cooling mechanism besides the shear instability is the turbulence also generated by wind stress (Chan and Kepert, 2010). Both are irreversible processes that produce mixed-layer deepening. The mixing transports heat vertically from the sea surface to the subsurface, appearing as a subsurface warming corresponding to the near-surface cooling, which is apparent in Fig. 2 with a peak at $\sim 50-100 \mathrm{~m}$.

Figure 2 shows a subsurface $(30-200 \mathrm{~m})$ cooling within $1^{\circ}$ of the track, and a subsurface warming on both sides of the track between \pm 2 and $4^{\circ}$ from the storm center, consistent with previous results (e.g., Price, 1981; Sanford et al., 2011). These warming signals contain relatively large uncertainties (the standard error ranges from 40 to $100 \%$ of the absolute value of the signals) compared with surface signals, partly because they occur within the thermocline that exhibits

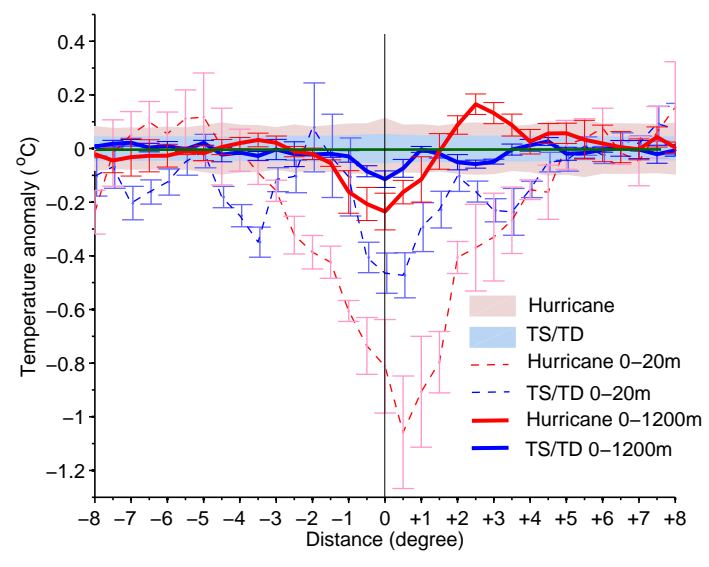

Figure 3. The 0-3-day averaged temperature change as function of distance across the cyclone center for hurricanes (red) and TS/TD (blue), in TC track coordinates. The values are smoothed using a three-point $\left(1.5^{\circ}\right)$ moving filter. Light blue shading shows the $90 \%$ confidence interval of background noise based on null-hypothesis analyses for TS/TD, and the light pink shading is for hurricanes. Surface temperature anomalies are presented as the thin curves, and the thick curves show $0-1200 \mathrm{~m}$ averaged temperature changes. The error bars are $1 \mathrm{SD}$, which is calculated as follows: $90 \%$ percent of pairs are randomly selected, and then we calculate the thermal anomalies of these pairs. This process is repeated 200 times, so 200 samples of thermal anomalies are obtained, and the SD is calculated from thermal anomalies of these 200 samples.

higher variability. Our composite analysis of the response from Argo floats confirms that there is an Ekman pumping effect in the upper ocean (upper $200 \mathrm{~m}$ ), in that we observe a residual vertical motion within $1^{\circ}$ of the storm track, appearing as a net column-averaged cooling near the storm center, along with downwelling outside the storm center (Fig. 2a and b). It is also possible that instantaneous wind erosion plays a role in addition to upwelling (Jacob and Shay, 2003; James et al., 2011) for the upper ocean changes (upper $200 \mathrm{~m}$ ), in particular during slower storms that produce weaker nearinertial velocity responses. Despite smoothing out of inertial oscillations, the resultant subsurface warming is observable.

At depths greater than $200 \mathrm{~m}$, we find a weak cooling signal near the storm center and weak warming away from the storm. The weak cooling near the storm center (between -1 and $+1^{\circ}$ ) is significant down to $400 \mathrm{~m}$ for hurricanes and $200 \mathrm{~m}$ for TS/TD. These signals have large uncertainties, with standard errors up to $100 \%$ of the signals (Fig. 2d). The causes of these deep ocean responses are beyond the scope of this study, but they may be linked to vertically propagating waves (Ascani et al., 2010; Sriver et al., 2013). Comparison of the TC thermal response with background oceanic variability indicates that the major structure of TC-induced thermal changes is significant compared with the background variability, as highlighted by black lines in Fig. 2a, c.

The cross-track footprint of the oceanic thermal response is averaged over depth $(0-1200 \mathrm{~m})$ during days $0-3$ relative 
to storm passage (Fig. 3), and we highlight the different characteristics of the response of the upper ocean $(0-20 \mathrm{~m})$ versus the entire column depth. Near the surface $(0-20 \mathrm{~m})$, for hurricanes, the cooling spreads to a large area of $\pm 5^{\circ}$ from the storm center, with a peak around $\sim-1.1^{\circ} \mathrm{C}$. In contrast, for TS/TD, we observe less cooling over a smaller area (a peak of $\sim-0.5^{\circ} \mathrm{C}$ ). The sea surface anomalies estimated by Argo observations are consistent with other SST observations presented by multiple previous studies (Lloyd and Vecchi, 2010, 2011; Mei and Pasquero, 2013).

For the response of the entire ocean column, TS/TD generally cause cooling between -1 and $+3^{\circ}$ in storm coordinates, implying that the dominant mechanism affecting columnintegrated temperature changes in TS/TD-affected regions is surface fluxes. The wind-driven entrainment itself does not change the ocean heat content of the whole water column, instead re-distributing the heat vertically via mixing. Ocean currents also advect mass and heat from their origin to different locations, but do not change the net ocean heat content. Therefore, if there is a net ocean heat content change over a TC-affected region, it must be via the ocean-atmosphere surface heat fluxes. A significant heat flux is also found in previous studies (Bell et al., 2012; Lin et al., 2009b; Mcphaden, 2009), and we expand on this discussion in the next section.

For hurricanes, the water column experiences a cooling within $\pm 2^{\circ}$ of the storm center, and stronger warming near between +2 and $+4^{\circ}$ along the right side of the track (in track coordinates). Both cold and warm peaks are significant at the $90 \%$ confidence level according to the null-hypothesis tests (see Appendix C). This implies that there is a net heat transport from the storm center to the right side of the storm relative to the storm's direction of motion. The magnitude of column-averaged cooling (within $+2^{\circ}$ of the storm center) is greater than the warming along the right side $\left(+2 \sim 4^{\circ}\right)$; thus, the net effect is a cooling of the upper ocean through enhanced surface fluxes.

\subsection{Estimate of air-sea heat flux}

Here we calculate a global estimate of air-sea heat exchange during TCs by integrating the ocean heat differences within storm-affected regions during a 3-day interval surrounding storm passage. We assume that during this period, the net column-integrated ocean heat loss is caused by heat transfer from the ocean to the atmosphere. We use the footprint methodology, which has two spatial dimensions: vertical depth and cross-track distance relative to the storm's direction of motion. Thus, the footprint represents a twodimensional insulated box that is $\pm 8^{\circ}$ across the storm track relative to the storm center and $1200 \mathrm{~m}$ deep, with an opening at the air-sea interface. The heat exchange between the box and its surroundings occurs only at the surface.

To test whether assumptions about the footprint hold, particularly related to insulation from horizontal advection at the sides of the box and vertical heat exchange at the base, we

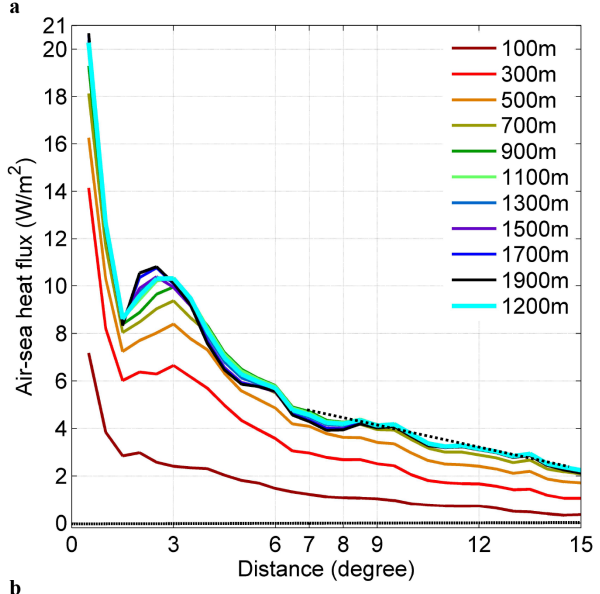

b

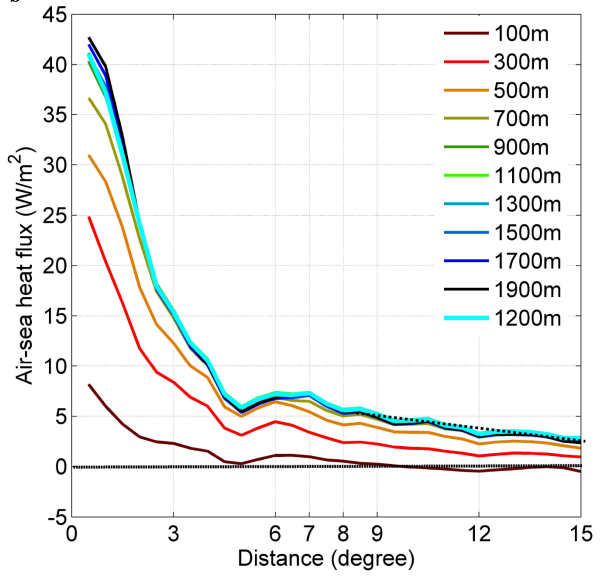

Figure 4. Estimates of air-sea heat flux within TC with different footprint domain sizes (horizontal and depth) for (a) TS/TDs and (b) hurricanes. The results of $1200 \mathrm{~m}$ are highlighted in cyan.

calculate the box-averaged air-sea heat flux at different horizontal and vertical spatial scales, ranging from $\mathrm{d} x= \pm 1^{\circ}$ to $\pm 15^{\circ}$ (with $0.5^{\circ}$ increment) and $\mathrm{d} z=100 \mathrm{~m}$ to $1900 \mathrm{~m}$ (with $200 \mathrm{~m}$ increment). As shown in Fig. 4, the averaged airsea heat flux stabilizes for $\mathrm{d} x>\sim 6^{\circ}$. The decreasing trend for $\mathrm{d} x>\sim 7^{\circ}$ is a "dilution" effect, which is caused by enlarging the box size while the OHC change within a TCaffected region remains unchanged. Note this effect is generally linear for large $\mathrm{d} x$, which is expected since the depth is held constant. In the vertical direction, the air-sea flux estimates are unchanged for $\mathrm{d} z$ greater than $700 \mathrm{~m}$ (corresponding to $\mathrm{d} x>\sim 5^{\circ}$ ). This result suggests the method requires at least $\pm 7^{\circ}$ and $700 \mathrm{~m}$ in order for the insulated box assumption to be considered valid. Thus, we use a terminal depth $\mathrm{d} z=1200 \mathrm{~m}$ based on the availability of data in the upper ocean (a large portion of Argos stop near $1200 \mathrm{~m}$ ), and $\mathrm{d} x=8^{\circ}$.

The annual contribution of TCs to the air-sea heat fluxes for $\mathrm{d} x=8^{\circ}$ and $\mathrm{d} z=1200 \mathrm{~m}$ is about $\sim 4.80 \mathrm{~W} \mathrm{~m}^{-2}$ and $\sim 6.25 \mathrm{~W} \mathrm{~m}^{-2}$ for TS/TD and hurricanes, respectively. The positive heat flux represents the net ocean heat loss. We cal- 


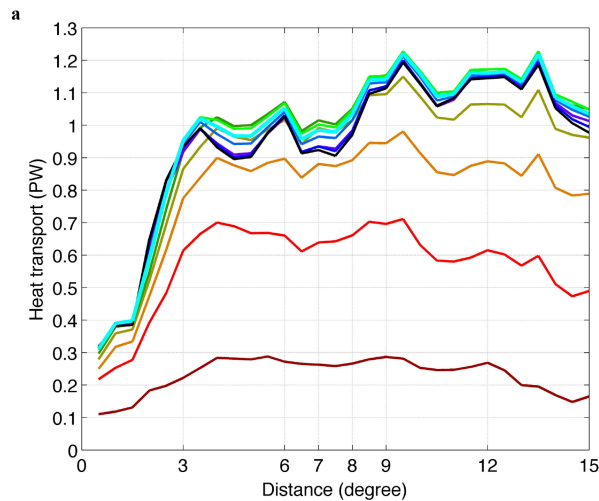

b

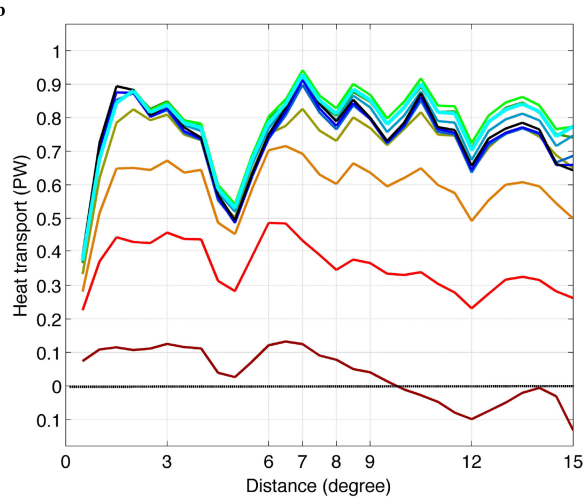

Figure 5. The impacts of domain size on global annual heat transfer from the ocean to the atmosphere by TCs for (a) TS/TDs and (b) hurricanes. The colors are the same as those in Fig. 4.

culate the total global air-sea heat exchange in Fig. 5. Given the methodology described previously, the integrated heat transport should converge to the total TC contribution, as we increase the domain size. Consistent with Fig. 4, this convergence occurs for $\mathrm{d} x>\sim 6^{\circ}$. For TS/TD, heat exchange continues to increase to $\mathrm{d} x>9^{\circ}$. However, this increase is probably not caused by TCs given the large spatial scale. Therefore, we estimate the global annual air-sea heat exchange during TCs to be 1.05 and $0.82 \mathrm{PW}$ for TS/TD and hurricanes, respectively. The total heat transfer is $1.87 \mathrm{PW}$ annually, which represents the total heat loss from ocean to atmosphere during the forced stage (0-3 days).

The global air-sea fluxes derived in Fig. 4 correspond to $584 \mathrm{~W} \mathrm{~m}^{-2}$ for TS/TD and $761 \mathrm{~W} \mathrm{~m}^{-2}$ for hurricanes, when averaging fluxes within storm-affected regions $\left( \pm 8^{\circ}\right.$ across the track). These values are consistent with previously published case study estimates, such as the mooring observations during the category-4 hurricane Nargis (Lin et al., 2009; Mcphaden et al., 2009), which estimated storminduced air-sea fluxes of $\sim 400-900 \mathrm{~W} \mathrm{~m}^{-2}$. Furthermore, our global estimates are consistent to first order with the estimated heat required to bring the troposphere into thermodynamic equilibrium (Emanuel, 1991) with the ocean of $\sim 10^{8} \mathrm{~J} \mathrm{~m}^{-2}$, which is equivalent to $\sim 3 \mathrm{~W} \mathrm{~m}^{-2}$ annually over the global ocean basin. This estimate generally agrees a

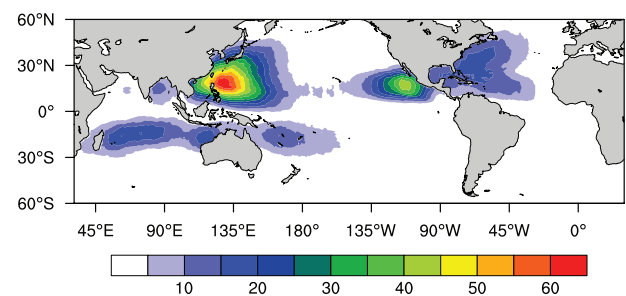

C.
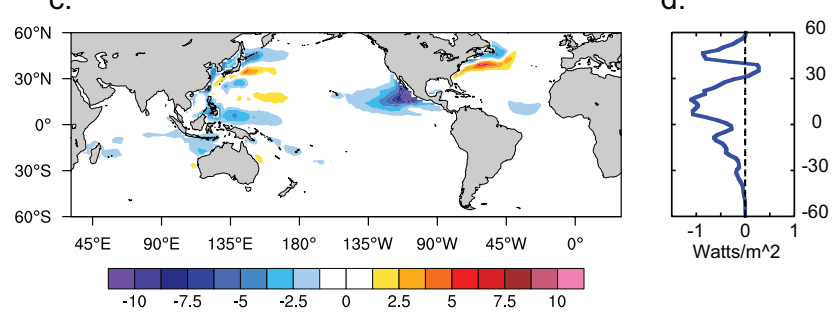

Figure 6. Geographical pattern of air-sea heat flux caused by TCs. (a) Globally integrated heat flux caused by TCs calculated using Argo float data $\left(\mathrm{W} \mathrm{m}^{-2}\right)$. (b) Zonally averaged TCinduced heat flux (red curve), compared with the annual climatology (1990-2010) of air-sea latent heat flux (black curve) derived from NCEP/NCAR reanalysis (Kalnay et al., 1996). (c) Surface flux (positive upward) along storm tracks for climatological conditions during the period 1990-2010 $\left(\mathrm{W} \mathrm{m}^{-2}\right)$, derived from NCEP/NCAR reanalysis using storm tracks from 1990 to 2010. The plot represents the background air-sea flux contribution to the Argo analysis using the 20-year daily climatology. (d) Zonal average of the climatological net surface heat fluxes shown in (c).

with our results $\left(4.80\right.$ and $6.25 \mathrm{~W} \mathrm{~m}^{-2}$ for weak and strong storm categories, respectively). A recent observational study (Bell et al., 2012) shows that the mean TC enthalpy fluxes from the CBLAST field program increase from $764 \mathrm{~W} \mathrm{~m}^{-2}$ at wind speeds of $52 \mathrm{~m} \mathrm{~s}^{-1}$ (category 3) to $2189 \mathrm{~W} \mathrm{~m}^{-2}$ at wind speeds of $72 \mathrm{~m} \mathrm{~s}^{-1}$ (category 5) near the storm center. The result of the category-3 conditions is similar to our estimate averaging over all hurricanes (category 1 to 5). In addition, Braun (2006) estimates a 1.34 PW heat loss from the ocean caused by hurricanes, which is $\sim 0.52 \mathrm{PW}$ larger than our estimate. Trenberth et al. (2007) estimate the TCinduced enthalpy exchange caused by hurricanes is about $0.58 \mathrm{PW}$ in total for 1990-2005, ranging from $628,703,783$ and 895 to $1019 \mathrm{~W} \mathrm{~m}^{-2}$ for categories 1 to 5, respectively, where the category- 3 estimate is similar to our estimates averaged over all hurricane conditions. In total, their result is about 0.24 PW smaller than our result for similar conditions. As noted previously, the 3-day averaging period used here may capture some of the recovery stage associated with a reversal of air-sea fluxes and the reheating of anomalously cold surface waters after storm passage; thus, these results may be considered slightly conservative compared to previous estimates (e.g., Braun, 2006). 

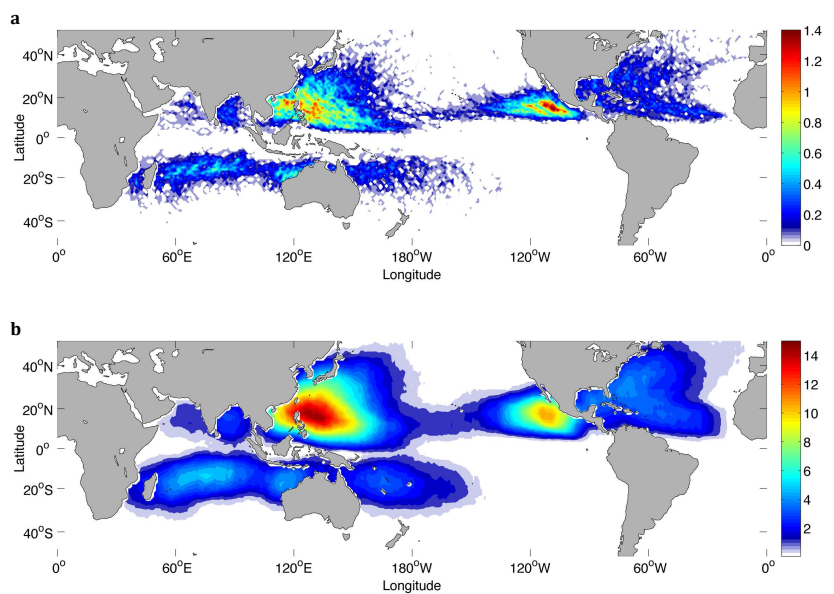

Figure 7. Frequencies of tropical cyclones per year affecting $1^{\circ}$ by $1^{\circ}$ grid boxes, when the TC-affected region is assumed to be (a) $\pm 1^{\circ}$ from the track center and (b) $\pm 8^{\circ}$ from the track center.

The geographical patterns of the TC-induced air-sea heat fluxes are presented in Fig. 6, using spatial and temporal averaging consistent with our global estimates. We find significant spatial variability in the flux estimates, with the largest fluxes occurring in regions with the most TC activity (i.e., the northwestern Pacific). These results indicate that the zonally averaged TC contribution to the total annual air-sea enthalpy flux budget may be as large as $\sim 9.1 \mathrm{~W} \mathrm{~m}^{-2}$, with peak values of around $20 \mathrm{~W} \mathrm{~m}^{-2}$ at latitudes experiencing the most TCs. These fluxes could account for as much as $\sim 10 \%$ of the total annual ocean latent heat flux $\left(90-110 \mathrm{~W} \mathrm{~m}^{-2}\right)$ (Trenberth et al., 2009) derived using NCAR/NCEP reanalysis (Kalnay et al., 1996), shown as the black curve in Fig. 6b.

As a simple check of the TC contributions of net surface fluxes, we compare the results from Argo data to the background surface fluxes using the NCEP/NCAR reanalysis. Specifically, we calculate the net climatological airsea heat fluxes along TC tracks using NCEP/NCAR reanalysis for the same Argo sampling criteria $\left(\mathrm{d} x=8^{\circ}, \mathrm{d} t=0\right.$ 3 days). However, these climatological fluxes represent the daily averages over a 23-year period (1990-2012), rather than from specific TC days. In other words, the plot shows the surface fluxes along storm tracks for non-TC conditions. The NCEP/NCAR reanalysis product generally predicts a net oceanic heat uptake in background climatological conditions during TC seasons (Fig. 6c). In the absence of TCs, typical conditions would favor a net ocean heat uptake on the order of $1 \mathrm{~W} \mathrm{~m}^{-2}$ zonally averaged across the global ocean. This background warming signal is of opposite sign to the TC effect, which tends to cool the ocean through enhanced surface fluxes during the forcing stage.

Figure 6a shows a prominent peak in air-sea heat flux in the western Pacific Ocean, reaching values as large as $65 \mathrm{~W} \mathrm{~m}^{-2}$. Because this region experiences the most TC ac-

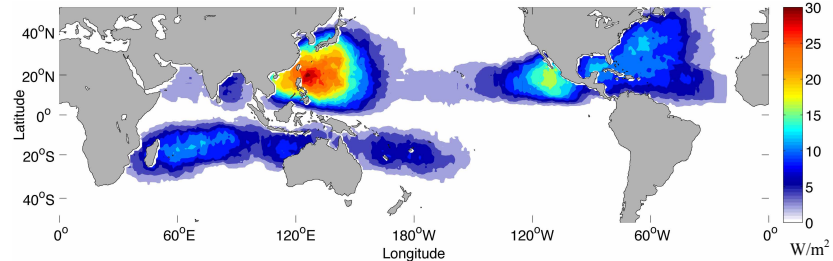

Figure 8. Geographical distribution of air-sea heat flux caused by TCs. We assume each grid box can only be affected by one storm within a 20-day window.

tivity, this peak is probably due to more TC occurrences relative to other regions.

In Fig. 7a and b, we present the frequency at each $1^{\circ}$ by $1^{\circ}$ grid box that is affected by TCs per year, given the affected regions (cross-track distance) defined to be \pm 1 and $\pm 8^{\circ}$ relative to the storm center. As expected, the figure shows a higher frequency of TC occurrences in grid boxes as we increase the size of the affected region. For example, in the western and eastern Pacific Ocean, between 1 and 1.5 storms pass directly through a single $1^{\circ}$ by $1^{\circ}$ grid box annually, but this activity can contribute as many as $12 \sim 14$ storms affecting the same grid boxes when we increase the TC-affected region to $\pm 8^{\circ}$.

To check whether the peak in heat flux is caused by increased frequency of TCs, we assume that one grid box can be affected by only one storm within 20 days. The annual air-sea heat fluxes for this method are presented in Fig. 8, showing that the peak fluxes in the northwestern Pacific decrease to $30 \mathrm{~W} \mathrm{~m}^{-2}$, while the overall fluxes in the other basins are relatively unaffected (to within $\sim 5-10 \mathrm{~W} \mathrm{~m}^{-2}$ ). Since the nature of air-sea heat exchanges is complicated by the close proximity of storms in active TC regions, such as in the northwestern and northeastern Pacific, our geographical map of air-sea heat flux should be regarded as a first-order approximation.

Here we use a bootstrap technique to constrain the error bars and characterize the uncertainties of our heat flux and OHC estimates. Beginning with the total number of Argo float samples (4410 pairs), we randomly choose $90 \%$ of pairs and repeat our air-sea heat flux and OHC anomaly calculations, as described in the previous sections. We repeat the calculation 200 times. In Fig. 9b, d, 200 estimates of air-sea heat fluxes are presented as a function of horizontal footprint size of the TC-affected regions (distance to the storm center). Most of these bootstrap estimates exhibit similar patterns to those shown in Fig. 4, supporting the robustness of our estimates. We choose an error bar of 1 standard deviation (SD) near $8^{\circ}$ to quantify the uncertainty of our estimate. This uncertainty measure is equal to $\pm 0.85 \mathrm{~W} \mathrm{~m}^{-2}$ for TS/TD and $\pm 1.50 \mathrm{~W} \mathrm{~m}^{-2}$ for hurricanes, which is equivalent to $\sim 20 \%$ and $\sim 25 \%$ of the fluxes for TS/TD and hurricanes, respectively. Or, in terms of global annual heat flux, this uncertainty equates to $\pm 0.20 \mathrm{PW}$ for TS/TD and $\pm 0.21 \mathrm{PW}$ for hurri- 

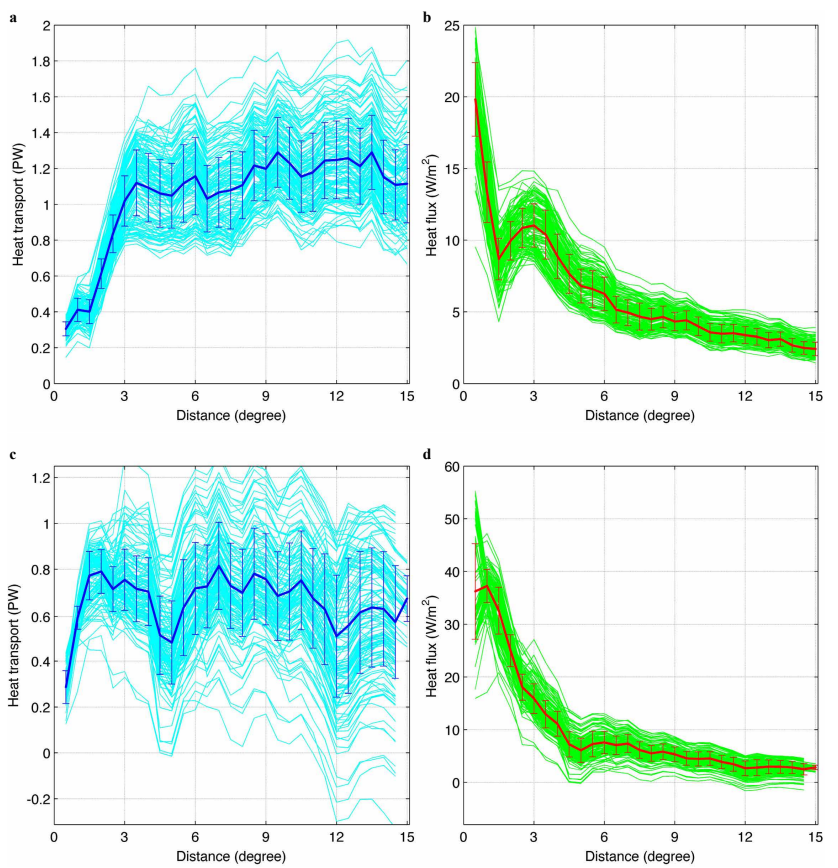

Figure 9. Two-hundred estimates of heat transport (in a and c) and air-sea heat flux (in b and d) based on 200 randomly selected samples of pairs. (a) and (b) are estimates under TS/TD conditions and (b) and (c) for hurricanes. The mean of 200 estimates is highlighted in blue for TS/TD and in red for hurricanes. Error bars represent the standard error.

canes (Fig. 9a, c), which is equivalent to $\sim 20$ and $\sim 25 \%$ of the total estimates for TS/TD and hurricanes, respectively. Including these uncertainties, our estimates of air-sea heat flux during the TC forcing stage ( $0-3$ days relative to storm passage) are $1.05 \pm 0.20 \mathrm{PW}\left(4.8 \pm 0.85 \mathrm{~W} \mathrm{~m}^{-2}\right)$ for TS/TD and $0.82 \pm 0.21 \mathrm{PW}\left(6.25 \pm 1.5 \mathrm{~W} \mathrm{~m}^{-2}\right)$ for hurricanes.

\subsection{The 4-20-day footprint of ocean thermal changes}

After storm passage, radiative forcing and ocean currents tend to restore the storm-induced surface anomalies. Past studies show that upper-ocean thermal anomalies can persist on the order of 10-20 days (Price et al., 2008), 2030 days (Dare and McBride, 2011), or even longer than 30 days (Mei et al., 2013; Mei and Pasquero, 2013; Park et al., 2011). Differences in timescales likely depend on differences in regional and seasonal ocean conditions (i.e., when and where TCs occur). Surface cooling is typically restored within 20 days according to satellite observations (Hart et al., 2007a), while thermal effects within the ocean interior may persist on inter-seasonal timescales (Jansen et al., 2010; Park et al., 2011). The mechanical energy is dispersed by continuous mixing near the surface and within the thermocline, as well as propagating internal waves to the larger ocean basin (Shay et al., 1989), with a delay of about 5-10 days (Price et al., 1983).
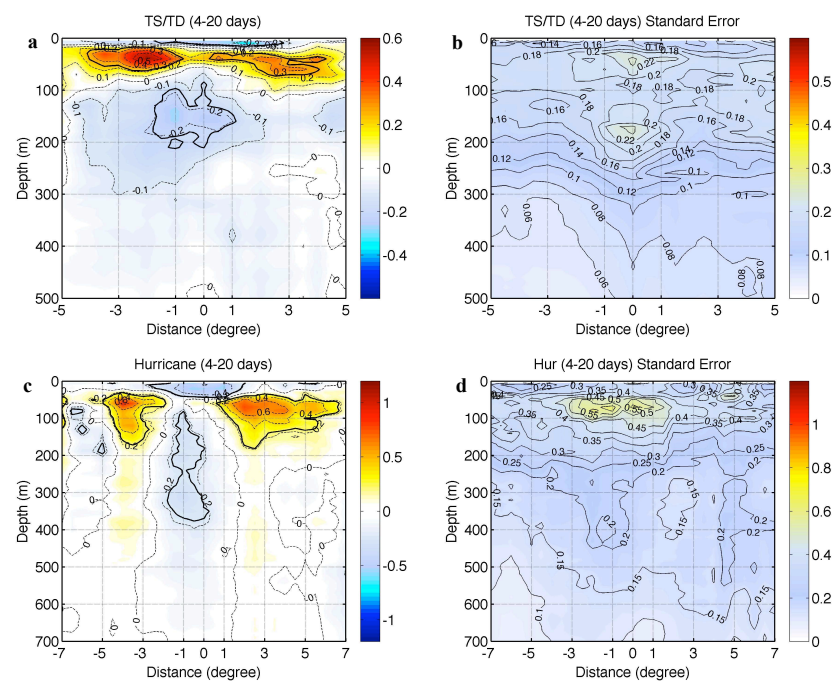

Figure 10. Vertical profile of the 4-20-day averaged ocean thermal changes (referenced to pre-storm conditions) from the track center for (a) TS/TD between +5 and $-5^{\circ}$ and (c) hurricanes between +7 and $-7^{\circ}$. The dashed contour interval in black is $0.1^{\circ} \mathrm{C}$ for TS/TD and $0.2^{\circ} \mathrm{C}$ for hurricanes. The solid black contours denote the signals that are significant at the $90 \%$ confidence interval. (b) and (d) show the standard error of the estimations corresponding to (a) and (c), respectively. The unit is ${ }^{\circ} \mathrm{C}$.

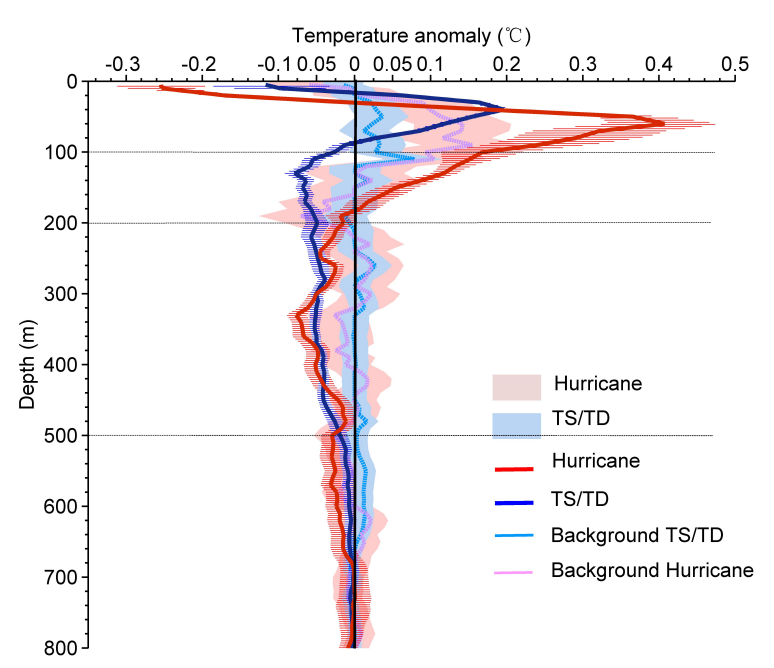

Figure 11. Vertical temperature change averaged within the -6 to $+6^{\circ}$ range from the storm center during the recovery stage (420 days) relative to pre-storm conditions. Blue and red lines represent TS/TD and hurricanes, respectively. Also plotted are the $90 \%$ confidence intervals in the null-hypothesis test (light blue and light pink shading for TS/TD and hurricanes, respectively). The light blue and pink curves show the mean background noise in TS/TD and hurricane subsets, respectively. The error bars represent the SDs, which are calculated by using the method as presented in Fig. 3 .

Here we present the vertical structure of the general temperature response between 4 and 20 days after storm passage 

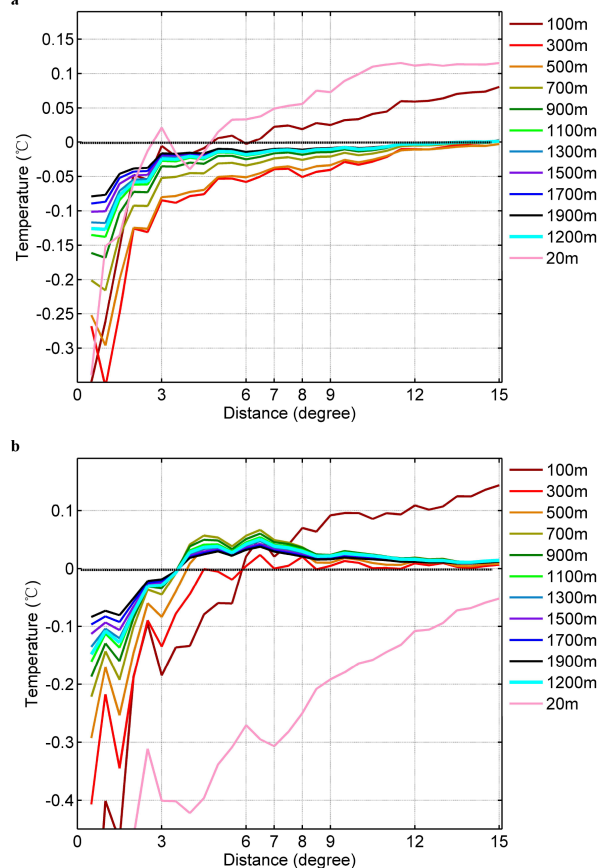

Figure 12. Column-averaged temperature anomalies within 4 20 days after tropical cyclones, relative to pre-storm conditions, as a function of the horizontal box size across the storm track (from $\pm 1^{\circ}$ to $\pm 15^{\circ}$ ) for (a) TS/TD and (b) hurricanes. The colors are different vertical sizes of the TC-affected box from 100 to $1900 \mathrm{~m}$. The results for the box with $1200 \mathrm{~m}$ depth are highlighted in cyan.

relative to pre-storm conditions (Fig. 10), which is representative of the ocean conditions in the restorative stage. Weak cooling still dominates the subsurface (100-200 m) response near the storm center. But, the standard error can be 100 $150 \%$ of the signal, maybe because of the longer time window (17 days in total). This weaker subsurface cold anomaly compared with the 0-3-day response implies that cooling caused by upwelling is being restored after storm passage, and this signal may be associated with the geostrophic ridge that develops in the wake of a storm following the dispersion of near-inertial waves (Geisler, 1970). In addition, the near-surface cold anomaly along the right side of the storm is still apparent during this restoration stage, thus pointing to the persistence of the TC signal.

Figure 10 shows persistent warm anomalies between 20 and $200 \mathrm{~m}$ along both the right and left sides of the storm tracks, which are greater in magnitude than the observed forced stage response ( $0-3$ days), with typical standard error (as a percentage of the TC signal) of 30-70\% for TS/TDs and $30-90 \%$ for hurricanes. However, we do not find similar temperature anomaly structures in the background variability for high TC activity basins (e.g., western Pacific), even when extending the background pair selection criteria to 40 and 60 days.
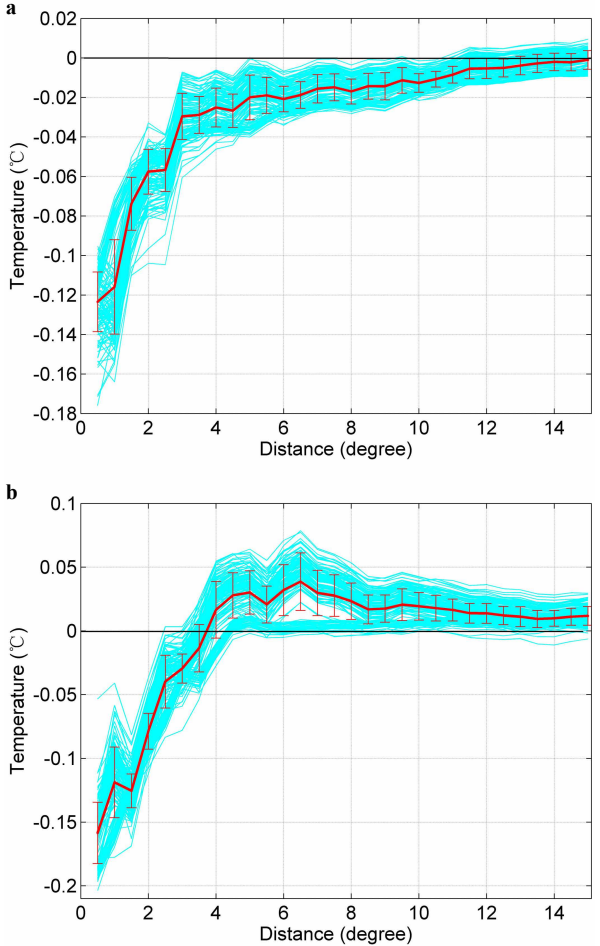

Figure 13. Two-hundred estimates (in cyan) of 0-1200 m columnaveraged temperature as a function of distance across the storm track, based on randomly sampling $90 \%$ of the Argo pairs for (a) TS/TD and (b) hurricanes, respectively. The mean and SDs are highlighted as the red line and error bars.

Figure 11 shows the vertical profile of the spatially averaged $\left(-6\right.$ to $\left.+6^{\circ}\right)$ thermal response during the TC recovery stage relative to pre-storm conditions. We find that vertical mixing and upwelling/downwelling induces significant cooling near the surface (0-20 m depth) and subsurface warming within the upper thermocline (50-200 m) for both TS/TD and hurricanes. The signals deeper than $200 \mathrm{~m}$ exhibit relatively weak cooling, and they are only significant for hurricanes near the storm center. As noted by previous studies, deep ocean (below $400 \mathrm{~m}$ ) thermal responses are rarely observed. One observation down to $530 \mathrm{~m}$ (Price, 1981) shows a large oscillation with amplitude about $30 \mathrm{~m}$ at the depth of $530 \mathrm{~m}$ after 10 days of storm passage. A study using a mooring observation (Brink, 1989) observed a TC-induced temperature oscillation at depths around $1000 \mathrm{~m}$. Because of the lack of observations, further modeling and theoretical studies are needed to understand the response of the interior ocean to extreme surface wind forcing below $200 \mathrm{~m}$.

\subsection{Estimates of $\mathrm{OHC}$ changes after storm}

It takes more than 20 days for the ocean subsurface to be fully restored to the normal conditions; therefore, in this study, we calculate $\mathrm{OHC}$ changes within 4 to 20 days after storms representative of the ocean conditions during the restorative 
stage. Temperature anomalies are plotted in Fig. 12 as a function of the spatial and vertical extents of the TC footprint. Within $3^{\circ}$ of the storm center, both TS/TD and hurricanes induce column-averaged cooling at all depths. The cooling effect decreases for increasing footprint size, approaching zero for TS/TD and a warming for hurricanes. This result suggests that upwelling and heat loss to the atmosphere near the storm center are partly (for TS/TD) or fully (for hurricanes) compensated by post-storm surface fluxes. Furthermore, when the footprint size is larger than $8-9^{\circ}$, the absolute value of the average temperature anomalies decreases, which is again attributable to the "dilution" effect as discussed in the previous section. The temperature anomalies also converge for increasing depth, when the footprint is greater than $3^{\circ}$. Thus, we use a cross-track length scale of $\sim 8^{\circ}$ and a depth scale of $1200 \mathrm{~m}$ to quantify the TC-induced upper ocean thermal response during the restorative stage. The average temperature anomalies for these footprint length scales are $+0.039^{\circ} \mathrm{C}$ for hurricanes and $-0.0125^{\circ} \mathrm{C}$ for TS/TD.

The annual contribution of the TC-induced $\mathrm{OHC}$ changes is calculated by multiplying the ocean temperature changes by yearly averaged track lengths. This method is based on our results that the averaged ocean thermal change over all storms between post-storm and pre-storm conditions is 0.039 and $-0.0125^{\circ} \mathrm{C}$ for hurricanes and TS/TD, respectively. The positive values indicate heat gained by the ocean. These estimates correspond to a global annual flux contribution of $\sim 5.98 \mathrm{~W} \mathrm{~m}^{-2}(0.75 \mathrm{PW})$ for hurricanes and $\sim-1.90 \mathrm{~W} \mathrm{~m}^{-2}$ $(-0.41 \mathrm{PW})$ for TS/TDs, where the positive values represent oceanic heat convergence.

Our results suggest that weak storms (TS/TD) tend to cool the ocean, while hurricanes tend to warm the ocean, when considering both storm-induced and post-storm fluxes. The difference in the ocean response may be due to the relatively weak vertical ocean mixing and surface cooling induced by TS/TD compared to hurricanes. For TS/TD, the OHC change is likely driven by the storm-induced enthalpy fluxes during passage. Because weaker storms typically cause less vertical mixing and thus less significant cold wakes following storms, there will be less post-storm heat flux into the ocean during the wake recovery stage. Conversely, strong events (hurricanes) induce more vertical mixing and surface cooling, which leads to more heat flux into the ocean during the recovery stage and thus oceanic heat convergence. This finding supports previous results using altimetry (Mei et al., 2013) and simplified approaches based on sea-surface temperature changes (Sriver and Huber, 2007 and Jansen et al., 2010).

Similar to calculating the uncertainties of 0-3-day OHC change, the 200 estimates of TC-induced OHC changes are shown in Fig. 13. We choose the uncertainty to be equivalent to the SD of the average temperature change for spatial extent of $8^{\circ}$ and $1200 \mathrm{~m}$, consistent with the heat flux estimate. This uncertainty equates to $\pm 0.0063{ }^{\circ} \mathrm{C}$ for $\mathrm{TS} / \mathrm{TD}$ and $\pm 0.0143^{\circ} \mathrm{C}$ for hurricanes, which represents $\sim 50 \%$ and $36 \%$ of the estimated OHC changes for TS/TD and hurricanes, respectively. Considering this uncertainty, our estimates of TC-induced thermal changes are $-0.0125 \pm 0.0063^{\circ} \mathrm{C}$ for $\mathrm{TS} / \mathrm{TD}$ and $0.0390 \pm 0.0143^{\circ} \mathrm{C}$ for hurricanes. Equivalently, these estimates correspond to global annual heat flux of $-0.41 \pm 0.21 \mathrm{PW}\left(-1.90 \pm 0.96 \mathrm{~W} \mathrm{~m}^{-2}\right)$ for all TS/TD, and $0.75 \pm 0.25 \mathrm{PW}\left(5.98 \pm 2.1 \mathrm{~W} \mathrm{~m}^{-2}\right)$ for all hurricanes, where the positive values denote an oceanic heat convergence.

These findings indicate the total TC contribution to the global ocean heat convergence is estimated to be $0.34 \mathrm{PW}$ annually in the 2004-2012 periods, which reflects an ocean heat gain from the atmosphere due to all storms.

\section{Caveats}

The methodology presented here contains several key caveats and limitations. One outstanding question relates to the accuracy of the no-TC pairs in capturing the interannual variability in the timing of events. In other words, given that years with tropical cyclones are likely to have different positioning/intensity of major atmospheric circulation patterns such as subtropical highs, one could expect to see a Rossby wave response from such shifts resulting in potentially anomalous trends at depth. To address this issue, we conducted the following test.

TC-affected pairs are subdivided into two subsets: one contains data from 2004 to 2008 and the other from 2009 to 2012 . We subdivide storms to analyze the sensitivity of our footprint results to different spatial patterns of storm locations. The results for TS/TD and hurricane 4-20-day footprints are presented in Fig. 14, both compared with the 20042012 results in black contours. In the figure, the main pattern is similar for the two time periods, with only some strength differences of the signals. In addition to this test, we calculate footprints of the background pairs for the two periods (not shown), and the differences are within the limit of insignificant noise. Results support the notion that the background signals can be mostly smoothed out by using a footprint strategy when averaging over large amounts of data with variant time and spatial distributions.

An additional caveat relates to vertically propagating waves forced by the storms. For example, mooring data have shown evidence of vertically propagating Rossby waves. Unfortunately, our method may not be able to distinguish the effects of these evanescent waves due to the following: (i) these non-permanent signals may be filtered by averaging a large amount of data over a long period of time, and (ii) we do not observe any such wave structure or patterns in our analysis (such as thermal anomaly across track in Figs. 2 and 10). However, the potential effect of vertical propagating waves on upper-ocean temperature and energy budgets remains an active area of research (Ascani et al., 2010; Sriver et al., 2013). 

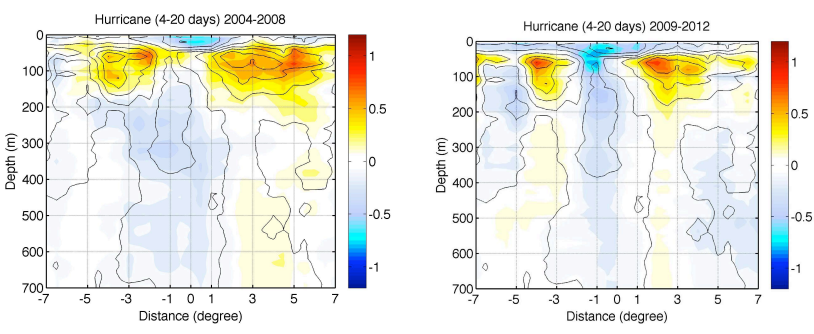

TSTTD (4-20 days) 2004-2008
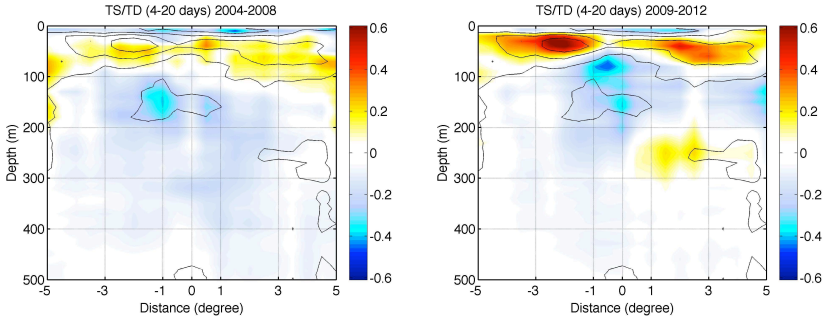

Figure 14. The 4-20-day averaged ocean thermal changes detected by using data from two year periods: 2004-2008 in the left panel and 2009-2012 in the right panel, shown in colors. The black contours are the result when using all of the data from 2004 to 2012, the same as the contours in Fig. 10. The results of hurricanes are presented in the top panel and the bottom panel for TS/TD. The unit is ${ }^{\circ} \mathrm{C}$.

Ocean stratification varies regionally, which can in turn pose problems for estimating global averages of ocean responses to TCs. To quantify the effect of regional variability, we calculate TC-induced ocean thermal changes within 4-20 days within three ocean basins separately: the Pacific Ocean, Indian Ocean and Atlantic Ocean. Note that we also subdivide the Pacific basin into separate regions - western/eastern/southern Pacific). Figure 15 shows the results in the footprint composite format. Key findings include that (i) the global-averaged thermal footprint pattern (Fig. 10c) is generally consistent with the pattern in the Pacific Ocean, especially in the western Pacific (Fig. 15a, d), since there are $\sim 2500$ pairs from the Pacific Ocean (or roughly $\sim 60 \%$ of the total number of pairs globally); and that (ii) although the footprints within the Atlantic and Indian oceans have large uncertainties, key characteristics of the general patterns are robust, such as ocean cooling near the storm center from the surface to subsurface $(0-200 \mathrm{~m})$ and subsurface warming along both sides of the track (Fig. 15e, f). However, only 25 and $15 \%$ of the Argo pairs globally are sampled from the Indian Ocean and Atlantic Ocean, respectively; thus, physical interpretations are limited by the relative lack of data. In the eastern Pacific, the ocean responses seem to be different from other regions, which appears cooling at the left side of TCs as shown in Fig. 15b. This difference may be due to the lack of data in this region, indicating that our method is insufficient to reconstruct the local responses to TCs.
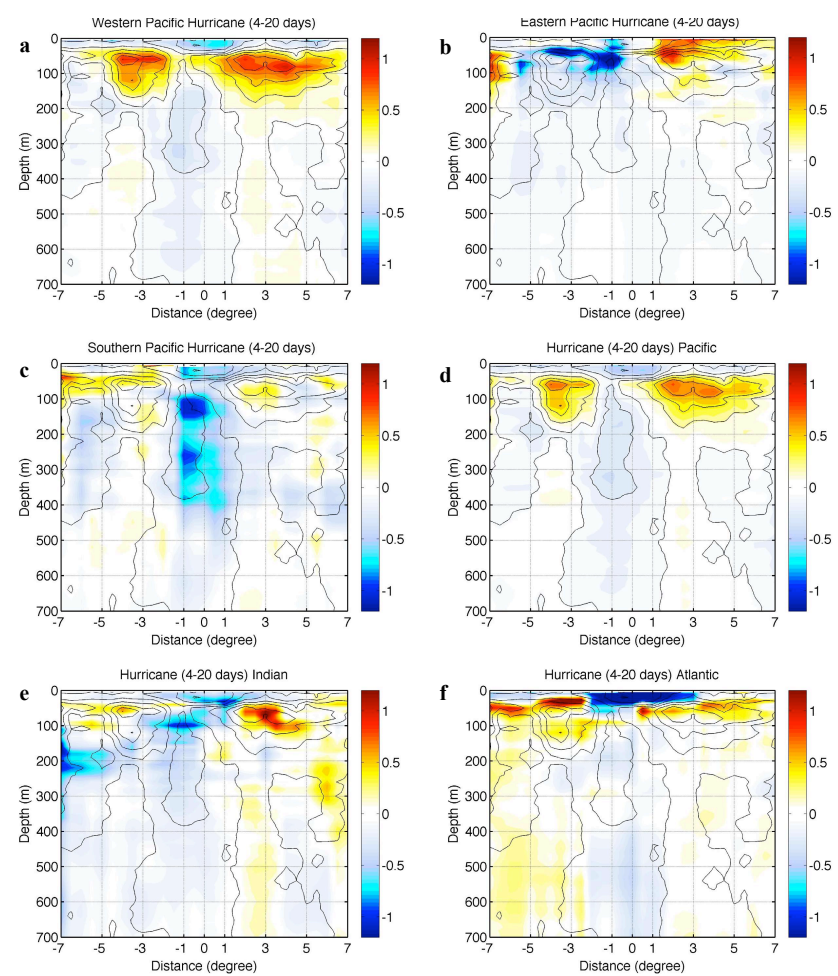

Figure 15. Ocean thermal changes induced by hurricanes within 4-20 days after storm passage for individual ocean basins: (a) in the western Pacific Ocean, (b) in the eastern Pacific Ocean, (c) in the southern Pacific Ocean, (d) in the Pacific Ocean, (e) in the Indian Ocean, and (f) in the Atlantic Ocean. The black contours are the global-averaged hurricane-induced ocean thermal changes in 4 20 days, which are the same as those in Fig. 10c. The unit is ${ }^{\circ} \mathrm{C}$.

\section{Conclusions}

We use Argo data to create a global representation of TCinduced changes in upper ocean temperature, using a new footprint method to create a composite analysis of the vertical profile of the cross-track ocean temperature response for two distinct timescales (0-3 and 4-20 days relative to storm passage) and categories (TS/TD and hurricanes). We find this method is capable of capturing the main characteristics of TC-induced ocean variability related to cross-track and intensity variations, as well as the differences in the response due to the choice of timescales (e.g., forcing versus recovery).

We find that during the storm passage, the ocean generally experiences a heat loss to the atmosphere through storm-induced enthalpy fluxes. Our observational results suggest that TCs contribute $11.5 \mathrm{~W} \mathrm{~m}^{-2}(1.87 \mathrm{PW})$ heat in TC-affected regions annually from the ocean to the atmosphere within 0 to 3 days after storm passage. Of this total, weak storms (TS/TD) contribute $4.80 \mathrm{~W} \mathrm{~m}^{-2}(1.05 \mathrm{PW})$ and strong storms (hurricanes) account for the rest. The uncer- 


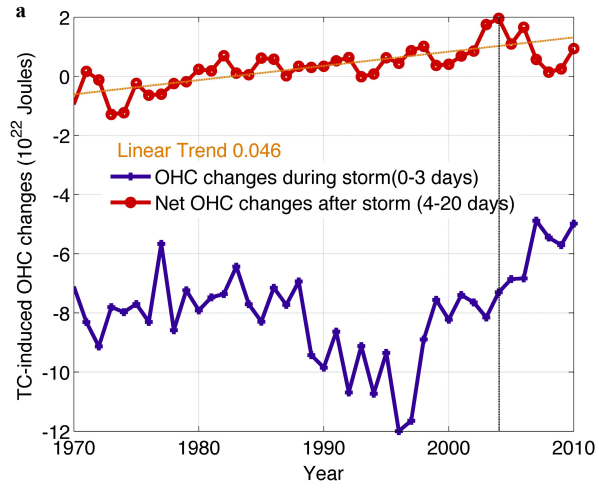

b

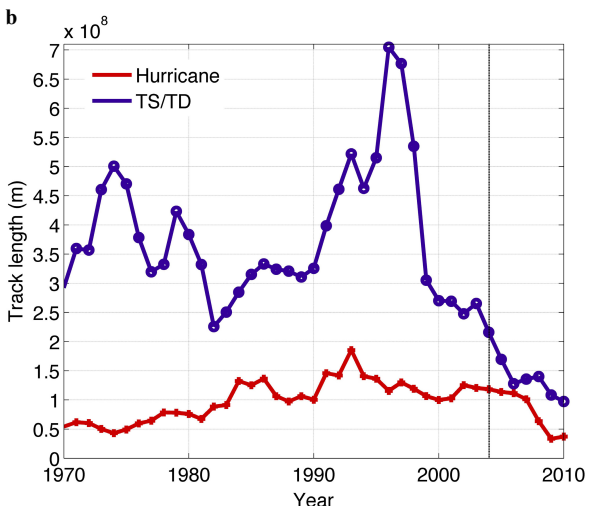

Figure 16. (a): the annual TC-induced ocean heat loss via air-sea heat flux in 0-3 days (blue line) and the ocean heat content changes after storms (in 4-20 days) (red line). The positive values show the ocean heat gain. The linear trend of the ocean heat gain is presented in pink, and the trend is $0.046 \times 10^{22} \mathrm{~J} \mathrm{yr}^{-1}$. (b): yearly averaged track lengths for both TS/TD (blue) and hurricanes (in red).

tainty of our estimate is about $20 \%$ for TS/TD and $25 \%$ for hurricanes.

Recent in situ, remotely sensed and reanalyzed air-sea heat flux products (Smith et al., 2011) have faced challenges in closing the ocean heat budget. These analyses show a global oceanic heat gain of 20-30 $\mathrm{W} \mathrm{m}^{-2}$ (Josey et al., 1999), while the global mean heat flux is $\sim 0.5 \mathrm{~W} \mathrm{~m}^{-2}$ from observed variations in $\mathrm{OHC}$. Our observational results suggest that TCs may provide a potential mechanism (heat flux in a high wind regime) for filling this gap.

After storm passage, ocean conditions in TC-affected regions experience a recovery process to at least partially restore upper-ocean conditions pre-storm or climatological values through enhanced air-sea fluxes leading to ocean heat convergence. This recovery stage lasts much longer than the forcing stage during the storm passage. We estimate the changes in a timescale of 4-20 days relative to pre-storm conditions, which implicitly includes fluxes during the forced stage. On this timescale, around $\sim 0.75 \mathrm{PW}\left(5.98 \mathrm{~W} \mathrm{~m}^{-2}\right)$ of heat is transferred annually from the atmosphere to the ocean for hurricanes, which represents an ocean heat gain after storms. However, TS/TD exhibit an opposite response, $\sim-0.41 \mathrm{PW}\left(1.90 \mathrm{~W} \mathrm{~m}^{-2}\right)$, representing an ocean heat loss for weaker events. We estimate the uncertainty to be about $50 \%$ of our estimates for TS/TD and $35 \%$ for hurricanes. The opposite sign of OHC changes after storm (4-20 days) for weak and strong storms implies that the impact of these events on the upper ocean is sensitive to the intensity. This result also suggests that additional atmospheric heating due to anthropogenic warming may potentially increase the rate of TC-induced ocean heat uptake, since research suggests the number of strong TCs may increase with continued warming (Bender et al., 2010; Knutson et al., 2010).

To assess the TC contribution to historical trends in the ocean heat uptake, we calculate the total air-sea heat flux in each year from 1970 to 2010, by assuming that each TS/TD transfers $6.25 \mathrm{~W} \mathrm{~m}^{-2}$ and each hurricane transfers $4.8 \mathrm{~W} \mathrm{~m}^{-2}$ heat from the $\mathrm{TC}$-affected region to the atmosphere during 0-3 days after storm. The annual heat flux is shown in Fig. 16 in blue. The figure shows a maximum atmospheric heating of $\sim 12 \times 10^{22} \mathrm{~J}$ during $1996 \sim 1997$ and a generally larger signal between 1988 and 1998, which is due to more TC activity during these years. As suggested in Trenberth and Fasullo (2007), the El Niño activity during these years (three between 1990 and 1995 and a large event in 1997-1998) may be at least partially responsible for this boost of TC activity in the western Pacific.

Figure 16 also shows the accumulated TC-induced OHC changes in recovery stages (4-20 days) relative to pre-storm conditions. We assume the $\mathrm{OHC}$ change is $-1.9 \mathrm{~W} \mathrm{~m}^{-2}$ for TS/TD and $5.98 \mathrm{~W} \mathrm{~m}^{-2}$ for hurricanes (a positive value shows a heat gain by the ocean). OHC changes show that TCinduced ocean heat convergence has been increasing since 1970. This OHC change is likely due to the increase in the fraction of strong storms during the past 40 years (Knutson et al., 2010). The linear trend of TC-induced ocean heat uptake is about $0.046 \times 10^{22} \mathrm{~J} \mathrm{yr}^{-1}$, which is $11 \%$ of global ocean heat uptake of the uppermost $2000 \mathrm{~m}$ during the past 55 years $\left(\sim 0.42 \times 10^{22} \mathrm{~J} \mathrm{yr}^{-1}\right)$ (Levitus et al., 2012).

In summary, the ocean response to TCs is complex. It is not a simple surface cooling and subsurface warming everywhere in TC-affected regions. It is highly variable, with upwelling/divergent currents near the storm center and downwelling/convergent currents in the outer regions, entrainment in the mixed layer, inertial oscillations of vertical/horizontal currents (Price, 1983), and maybe other differences in the response due to TC characteristics such as translation speed (Emanuel, 2007). Our results indicate that TCs are an important component in the ocean system, providing a link between variability in air-sea heat flux and ocean heat uptake. 


\section{Appendix A: The composite footprint method}

As discussed in Sect. 2.2, we introduce a footprint method that averages all of the TC-induced cross-track (i.e., perpendicular to the storm's direction of motion) ocean temperature changes. We define TC-induced ocean thermal changes calculated from Argo pairs using the functional form

$\mathrm{d} T_{a 1}=\mathrm{d} T_{a 1}(\mathrm{ID}$, dist, track, depth, $\delta t)$,

where ID identifies the particular storm, dist is the distance between the observation location and the track center perpendicular to the storm's direction of motion (the cross-track distance in the storm coordinate system), track denotes the spatial location of an Argo pair related to a TC track (the alongtrack distance in the storm coordinate system), depth denotes the vertical depth of the temperature anomalies, and $\delta t$ is the time difference between the observing time of the TCaffected Argo profile and the time of the nearest track center. We define the positive values of dist to be consistent with the asymmetric inertial response (to the right in the Northern Hemisphere and to the left in the Southern Hemisphere), referred to as TC-track coordinates (Price et al., 2008).

To create a composite representation of the average ocean response, we reduce the five-dimensional function $\mathrm{d} T_{a 1}$ to a three-dimensional function by averaging the anomalies over all TC conditions corresponding to two predefined categories (TS/TD and hurricanes). We define a track-averaged footprint of ocean thermal changes over all tracks, and we separate the events into two distinct categories: TS/TD and hurricanes. Track locations with maximum wind speeds less than 63 knots are categorized as TS/TD, and all others are categorized as hurricanes (this hurricane category represents conditions when a TC is in hurricane status). The footprint is represented as

$F_{\mathrm{TSTD}}($ dist, depth, $\delta t)=$

$\sum_{\mathrm{ID}=1}^{\mathrm{ID}=n_{\mathrm{TSTD}}}\left[\mathrm{d} T_{a_{1}}(\mathrm{ID}\right.$, dist, track, depth, $\left.\delta t) d_{\text {track }}\right] / n_{\mathrm{TSTD}}($ dist, depth, $\delta t)$,

$F_{\text {Hur }}($ dist, depth, $\delta t)=$

$\sum_{\mathrm{ID}=1}^{\mathrm{ID}=n_{\text {Hur }}}\left[\mathrm{d} T_{a_{1}}(\mathrm{ID}\right.$, dist, track, depth, $\left.\delta t) d_{\text {track }}\right] / n_{\text {Hur }}($ dist, depth, $\delta t)$.

In these equations, the $\mathrm{d} T_{a}$ is the observational temperature anomaly. The number of the temperature anomalies at each dist, depth and $\delta t$ is denoted as $n_{\mathrm{TSTD}}$ and $n_{\mathrm{Hur}}$ for TS/TD and hurricanes, respectively.

We construct the three-dimensional footprints by grouping temperature anomalies from TS/TD and hurricanes, respectively, with dimensions dist containing $0.5^{\circ}$ bins from -8 to $+8^{\circ}$ across the track, $\delta t$ containing 0.5-day bins from 0 to 20 days, and depth containing $10 \mathrm{~m}$ bins from 5 to $1000 \mathrm{~m}$ and $50 \mathrm{~m}$ bins from 1000 to $2000 \mathrm{~m}$. In each grid box, averages of the temperature anomalies are calculated by using temperature anomalies from this box and 14 other adjacent

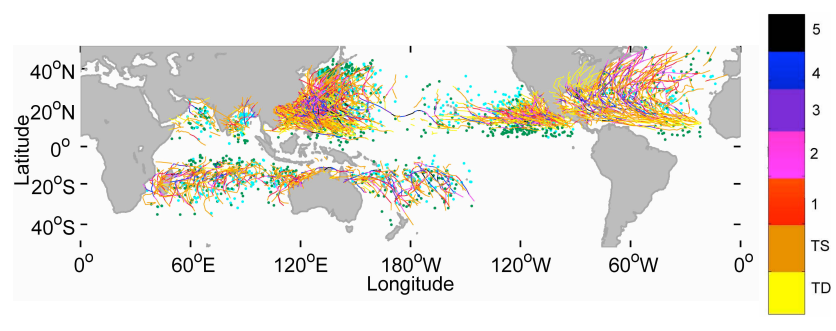

Figure A1. Tracks of tropical cyclones from January 2004 to December 2012, associated with the distribution of Argo pairs used in the paper. The colors of the tracks indicate the categories of tropical cyclone-tropical depression (TD; yellow), tropical storm (TS; orange), and category 1-5 cyclones (denoted by red, magenta, purple, blue, and black from categories 1 to 5, respectively). The locations of Argo pairs are dotted in two colors: cyan dots are the pairs located at the right side of the corresponding TC track, and green dots are the pairs located on the left side of the track. We analyze 885 tracks and a total of 4410 Argo pairs.

bin boxes (in time and dist, dimensions between -0.5 and 0.5 days, and -1 to $1^{\circ}$ relative to the given box).

We use this strategy to capture the main variability of the ocean response and to avoid potential biasing caused by the uneven distribution of Argo pairs in space and time. Key points of this methodology include (1) categorizing the events into weak and strong events/conditions, and (2) focusing on the cross-track temperature response, using a footprint technique that neglects along-track variability. Point (2) reflects the assumption about the importance of the asymmetric cross-track thermal response compared to along-track directions, which has been noted in numerous previous case studies (Black and Dickey, 2008; Deal, 2011; Price et al., 2008). However, recent studies (Jaimes and Shay, 2010; James et al., 2011) suggest ocean variability along the track can substantially modulate the ocean cooling response to TC forcing and distort the temperature anomaly in the wake of the storm, which can be important within western boundary currents and associated geostrophic vortices. As a first step to determining TC effects on upper ocean thermal structure on a global scale, we focus primarily on the cross-track ocean response.

As stated previously, our methodology requires the distance between two Argo profiles in a pair to be less than $0.2^{\circ}$. However, we do not require the pre-storm and poststorm measurements to be recorded from the same float. This criterion is in contrast to recent regional analysis using Argo data (Park et al., 2011), which stipulated the constraints that two profiles are to be measured by the same Argo float in order to reduce the float-to-float calibration difference, and the maximum distance between measurements is to be less than $200 \mathrm{~km}$. In the current study, $\sim 80 \%$ of the pre-storm and post-storm measurements are from the same float.

Figure A1 shows the geographical distribution of the TC tracks along with all of the Argo pairs from January 2004 


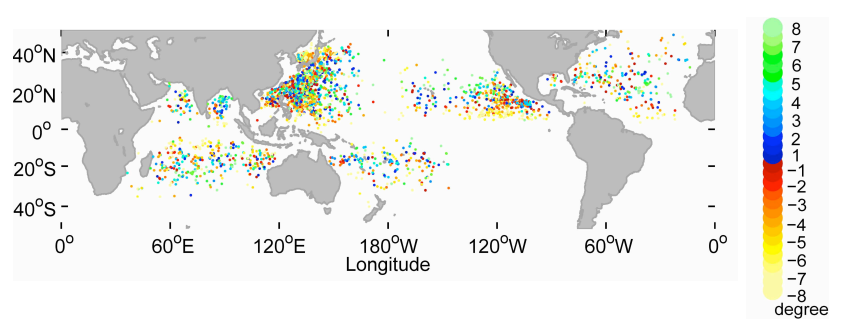

Figure A2. Locations of TC-affected Argo pairs with colors showing the cross-track distances of their locations relative to the corresponding storm track. Positive values indicate pairs to the right (left) side of the track in the Northern Hemisphere (Southern Hemisphere).

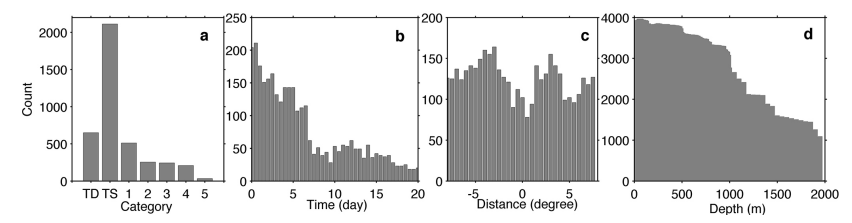

Figure A3. Histograms of the Argo float pairs for different statistics: (a) storm category, (b) time after storm passage (0.5-day bin), (c) distance from the storm center $\left(0.5^{\circ} \mathrm{bin}\right)$, and (d) depth $(10 \mathrm{~m}$ bin). In (c), a positive distance represents the right (left) side of the track in the Northern Hemisphere (Southern Hemisphere), and a negative distance represents the left (right) side in the Southern Hemisphere (Northern Hemisphere).

to December 2012, highlighting the global coverage of the Argo pairs in TC-affected regions (4410 total pairs). Tropical cyclones have preferred locations and directions of motion. For example, TCs in the northwestern Pacific move to the northwest between 10 and $20^{\circ} \mathrm{N}$ and northeast between 20 and $40^{\circ} \mathrm{N}$. This preferred storm location and direction of motion result in coastal pairs in the northwestern Pacific located on the left side of the tracks, while the pairs away from the coast are typically located on the right side of the tracks. In the northeastern Pacific, TCs generally move to the northwest, leading to a clear distribution of right-side pairs in $20-40^{\circ} \mathrm{N}$ and left-side pairs in $0-20^{\circ} \mathrm{N}$. Similarly, in the northern Atlantic, the distribution of TCs leads to the leftside pairs mainly being distributed between $0-15$ and 40 $50^{\circ} \mathrm{N}$. But, in the Indian and southern Pacific oceans, the left- and right-side pairs mix together. These preferred locations of TCs and the resulting distributions of Argo pairs (Fig. A2) can affect the geographical patterns of the TCinduced oceanic response.

The distributions of Argo pairs are presented in Fig. A3 for the category, observation time (relative to storm passage), depth, and distance from storm center. Fig. A3 reflects several key features of the methods and analysis, including (1) the uneven distribution of the data and (2) the larger number of Argo pairs for the TS/TD conditions than for hurricanes (TS/TD conditions are much more common). (3) The number of Argo pairs decreases with time (e.g., we sample more pairs between 0 and 10 days after storm passage compared to between 10 and 20 days). (4) We obtain the least number of pairs near storm centers. Point (4) may be due, in part, to unreliable Argo measurements associated with severe conditions near storm centers (bad profiles) and/or strong horizontal currents $\left(\sim 100 \mathrm{~cm} \mathrm{~s}^{-1}\right)$ advecting the floats away from the storm centers. To check whether there are some systematic differences (i.e., drifting) in horizontal distance between the two profiles in a pair, we calculate the horizontal difference between the two profiles as in Appendix D. In both geographical coordinates and track coordinates, we find no significant effects of drifting.

\section{Appendix B: Estimation of background variability in Argo pairs}

Isolating the TC-induced thermal changes using Argo floats is difficult, because biases can arise due to changes in the thermal structure of the background ocean state. These biases can be caused by many processes such as the seasonal cycle, meso-scale signals and large-scale spatial variability. Here we employ a test to examine potential biases and quantify background errors related to our footprint method described in the previous sections. Background noise is estimated by using Argo pairs under quiescent conditions (i.e., without TCs), hereafter denoted as NoTC pairs.

Our methodology for analyzing background variability is outlined in the following steps.

1. We collect all Argo profiles during January 2004December 2012 for which there are no TCs within $\pm 8^{\circ}$ distance of their location and -50 to +5 days relative to storm passage. These profiles are denoted as NoTC profiles.

2. Background Argo pairs are formed by using these NoTC profiles. The sampling strategy is the same as the TC pairs. One Argo pair consists of two Argo profiles, which are within $0.2^{\circ}$ and 20 days. Twenty days is set here to make this timescale comparable with the timescale of the typical TC response. We tested the sensitivity of the analysis to the choice of timescale by also analyzing variability out to 40 days. The results were consistent for both timescales.

3. The pairs are then spatially and temporally chosen according to TC track and TC-affected pairs. In each $4^{\circ}$ by $8^{\circ}$ grid box and 1-month time period during each year, if there is at least one TC-affected pair, background pairs detected in step (2) are flagged as "legal-NoTCpair" and all of the un-flagged pairs are removed. By using this strategy, all of the remaining pairs (NoTC pairs) are comparable to the TC-affected pairs for all locations and dates. Thus, for each storm track, background pairs are 
collected across all years corresponding to storm track locations and timing of events (within a given year). This sampling strategy provides a consistent method for analyzing background variability, by comparing Argo pairs from the same regions and times of year during storm (TC pairs) and non-storm (NoTC pairs) conditions.

4. To frame the background signals into the context of our footprint method, the NoTC pairs obtained in step (3) are converted to a background footprint (denoted as the NoTC-TSTD footprint and the NoTC-Hur footprint for TS/TD and hurricanes, respectively). To summarize the method, each TC footprint bin, for example $F_{\text {TSTD }}$ with a bin denoted by (dist, depth, $\delta t$ ), contains $n$ TC-affected pairs with geographical locations of $\left(\operatorname{lat}_{i}, \operatorname{lon}_{i}\right) i=1: n$. The NoTC-TSTD footprint (NoTCHur footprint) at the same bin (dist, depth, $\delta t$ ) is calculated by selecting $m$ NoTC pairs according to the locations of TC-affected pairs. If there exists a NoTC pair within $2^{\circ}$ to $\left(\operatorname{lat}_{i}, \operatorname{lon}_{i}\right)$, this NoTC pair is selected to calculate the NoTC-TSTD footprint (dist, depth, $\delta t$ ) (NoTC-Hur footprint (dist, depth, $\delta t$ )). In the construction of the background footprint, $m$ is set to $n$. In this case, we define background variability at a single location in terms of one NoTC pair. Using one NoTC pair corresponding to a given TC pair enables strict comparison between the two data sets. Otherwise, the method will yield more weight to individual pairs from locations with low TC activity (e.g., where there are many NoTC pairs compared to TC pairs). However, we have performed additional tests using all of the pairs from step (3), and the results are generally consistent with the constraints employed here.

By using the background pairs selected as above, both the NoTC-TSTD footprint and NoTC-Hur footprint are obtained according to the footprint method proposed in the previous section. In this case, the background signals can be directly comparable to the TC footprint ( $F_{\mathrm{TSTD}}$ and $F_{\mathrm{Hur}}$ ).

In total, 13701 pairs are collected after step (3) is conducted. All the Argo profiles are under the same quality control procedures as the TC-affected Argo profiles discussed in the previous section. Figure B1a and $\mathrm{b}$ display the total number of TC pairs and NoTC pairs in each $4^{\circ}$ by $8^{\circ}$ grid box. The spatial distribution of NoTC pairs is generally consistent with the TC-affected pairs.

The errors and biases due to the presence of background variability are quantified using two independent methods described in the following subsections. We first conduct a gross check on background error, and we quantify the background error using the footprint method.
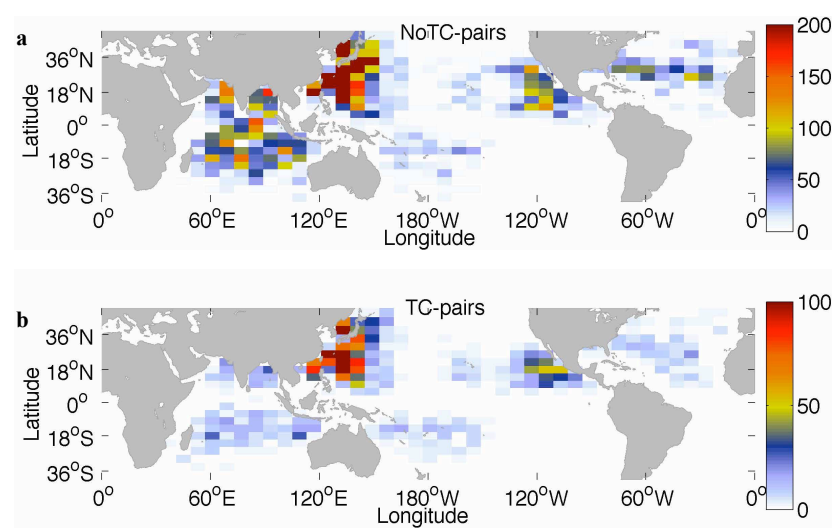

Figure B1. Counts of the (a) NoTC pairs and (c) TC-affected pairs in each $4^{\circ}$ by $8^{\circ}$ grid box.

\section{B1 Gross check}

By applying a gross check, we are aiming to check the magnitude of the global-averaged background signals and the size of the background uncertainties in TC-affected regions and seasons. We also compare the error with a standard Argo accuracy of $\sim 0.005^{\circ} \mathrm{C}$. We define the temperature differences of these NoTC pairs as background noise $\left(\mathrm{dBT}_{a}\right)$ using the functional form

$\mathrm{dBT}_{a}=\mathrm{dBT}_{a}($ time, $\delta t$, depth, lat, lon),

where time denotes the Julian day of the reference Argo profile; $\delta t$ is the time difference between the two Argo profiles in each pair; lat and lon denote the spatial locations of a pair; and depth is the depth of a temperature anomaly. These anomalies are collected in two maps to test for any systematical temporal or spatial biases in background pairs:

Back-Map1 $($ depth $)=$

$\int_{\text {day } 1}^{\text {day }_{2}} \int_{\delta t_{1} \text { lat } 1 \text { lon1 }}^{\delta t_{n}} \int_{\text {lat2 lon2 }}^{\text {lon }} \mathrm{d} T_{a_{1}}$ (day, $\delta t$, depth, lat, lon $) d_{\text {lon }} d_{\text {lat }} d_{\delta t} d_{\text {day }} / n$ (depth),

Back-Map2 $(\delta t)=$

day $_{2}$ depth $_{n}$ lat2 lon2

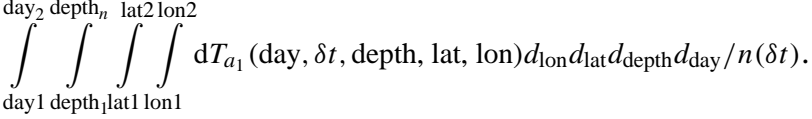

where $n$ (depth) and $n(\delta t)$ denote the number of pairs for each depth and each $\delta t$, respectively. In Back-Map1, all of the background temperature anomalies are grouped into bins representing $5 \mathrm{~m}$ thickness between 0 and $2000 \mathrm{~m}$ in depth. In Back-Map2, temperature anomalies are grouped into temporal bins of size 0.5 days between 0 and 20 days.

The mean and \pm 1 SD of the background noise as a function of depth and $\delta t$ are presented in Fig. B2. The means of the background noise with depth are near zero, with a very small positive temperature anomaly near the sea surface (20$100 \mathrm{~m}$ with the peak about $0.005^{\circ} \mathrm{C}$ ), which may be caused 

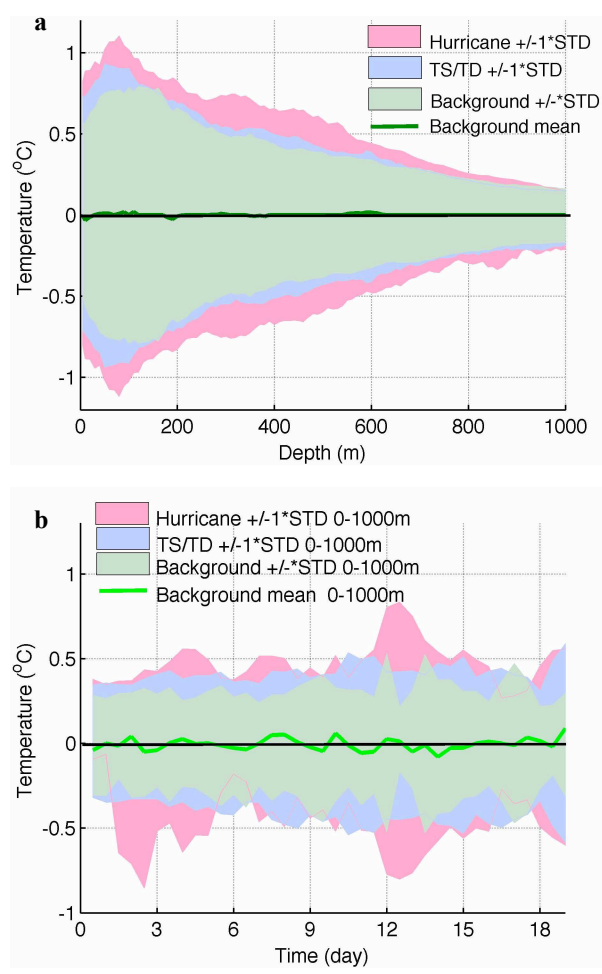

Figure B2. Background ocean temperature variability as a function of depth and time. (a) Mean (green curve) and 1 SD (green shading) of background variability as a function of depth, compared with 1 SD of hurricane and TS/TD affected pairs. (b) Time evolution of background variability of $0-1000 \mathrm{~m}$ average (light green line and light green shading for mean and SD, respectively). The SDs of temperature anomalies in Argo pairs under TS/TD and hurricane conditions are plotted in light blue and light red, respectively.

by seasonal/meso-scale signals. However, this anomaly is negligible compared to TC signals (discussed in the following sections).

The means of the background variability as a function of time also show no trend with $\delta t$ (Fig. B2b) for $0-1000 \mathrm{~m}$ (also no trend for 0-20 m; not shown here). The 0-1000 m averaged SDs of Argo pairs influenced by hurricanes and TS/TD show a $0.1-0.2{ }^{\circ} \mathrm{C}$ larger deviation compared to estimates of background variability, which shows that TCs can disturb normal ocean conditions and that the perturbation is observable using this methodological framework.

Next, we apply a bootstrap analysis to determine the effect of sample size on characterizing potential biases, errors, and background variability. At each depth, we randomly choose a certain number of pairs (the number of samples changes from 10 to 9000 , with a step size of 20), and we calculate the mean of the temperature anomalies of the chosen pairs. This procedure is repeated 200 times yielding 200 means, and we calculate the SD of the 200 means at each vertical level. Figure B3a shows the standard error at different depths against sample sizes, indicating that the error of the temper-

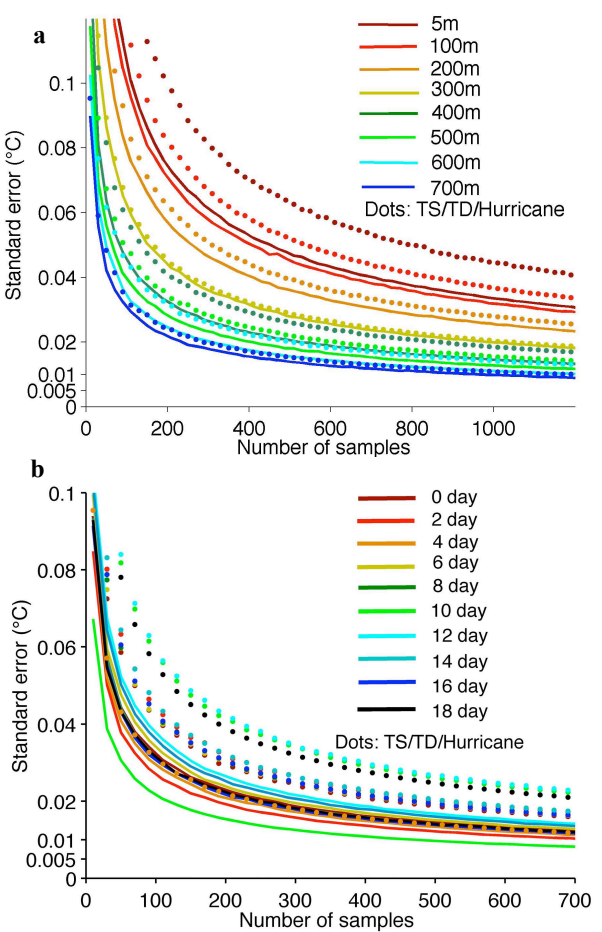

Figure B3. Bootstrap analyses of background noise. (a) Standard errors at different depth versus sample numbers with colors denoting different depths. (b) Standard errors at different times versus sample numbers with colors denoting different times. Solid lines are the results from using the whole NoTC pairs data set, and the dots show the same results for the TC-affected pairs.

ature anomalies decreases with sample size. When sample sizes are greater than 400 , the standard error at depths deeper than $400 \mathrm{~m}$ is less than $0.02^{\circ} \mathrm{C}$, and at depths less than $400 \mathrm{~m}$, the standard error is less than $0.06^{\circ} \mathrm{C}$. Both of these errors are less than $5 \%$ of SDs at corresponding depths shown in Fig. B3a. When the sample size is increased, the error is gradually reduced and converges near the Argo sensor accuracy $\left(0.005^{\circ} \mathrm{C}\right)$ for the upper shallow depths and below the Argo sensor accuracy for deeper levels. This result suggests that increasing the amount of data generally reduces the background error when averaged over large areas.

We consider the time evolution of background noise by randomly choosing a specific number of pairs (the number changes from 10 to 900, with a bin size of 20) and calculate the mean of the selected samples. This procedure is also repeated 200 times, and then we calculate the SD of the 200 time means. Figure B3b shows the standard error for different times as a function of sample sizes, showing a consistent error at different times in general. For sample sizes greater than 200 , the standard error is generally less than $5 \%$ of the SDs shown in Fig. B3b (e.g., less than $0.03{ }^{\circ} \mathrm{C}$ for all time differences). Considering that the Argo accuracy is $\sim 0.005^{\circ} \mathrm{C}$, the error we detected is several times larger than the Argo accuracy. 

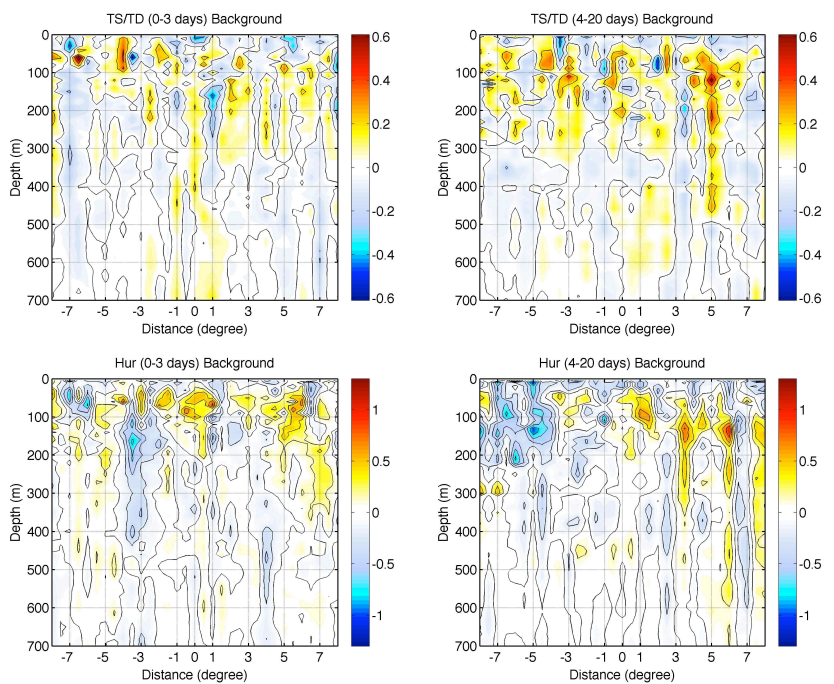

Figure B4. Background ocean thermal changes as a function of depth and distance in TC-track coordinates. The background footprint is created corresponding to a TS/TD footprint (a) on a 0-3-day average and (b) on a 4-20-day average, and to a hurricane footprint (c) on a 0-3-day average and (d) on a 4-20-day average. The contour interval is $0.2^{\circ} \mathrm{C}$ in black. The units are ${ }^{\circ} \mathrm{C}$.
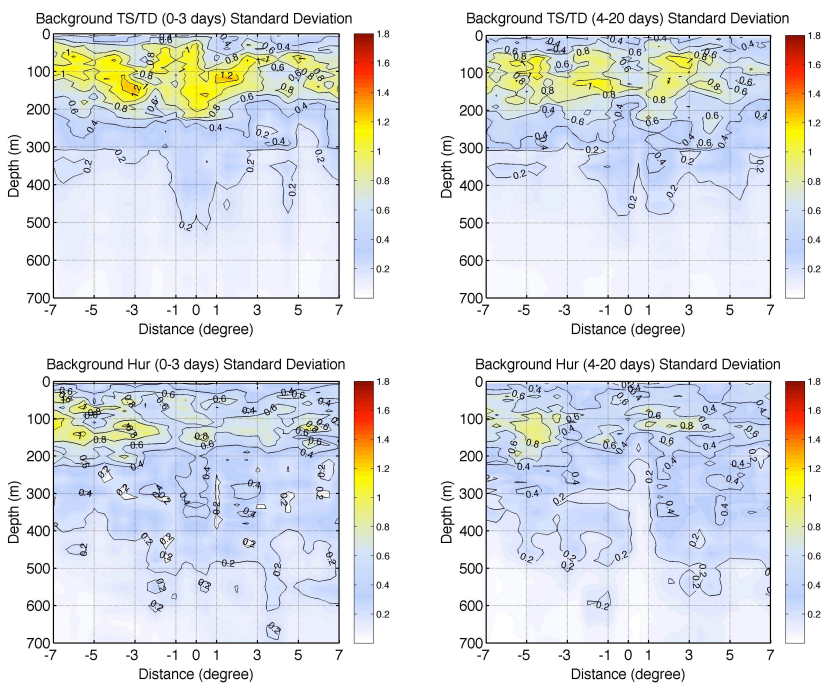

Figure B5. SD of the background footprints for TS/TD and hurricane locations, respectively, on two time periods: $0-3$ and 420 days. The unit is ${ }^{\circ} \mathrm{C}$.

\section{B2 Background footprint}

To be consistent with our method for quantifying TC-induced ocean thermal changes, we construct a similar footprint that is a composite based on background pairs. The NoTC-TSTD footprint and NoTC-Hur footprint are presented for two time periods: $0-3$ and $4-20$ days for TS/TD and hurricanes, respectively (Fig. B4). For TS/TD locations, the background thermal anomalies for the two time periods show no clear pattern at any depths or spatial locations across the track. Since these background pairs are selected according to the dates and locations of TC-affected pairs but in different years, we conclude that the footprint method produces no significant background patterns.

The SDs of the NoTC-TSTD footprint and NoTC-Hur footprint are presented in Fig. B5, corresponding to the mean of background footprints shown in Fig. B4. It appears that the SDs show a similar vertical distribution for the two time periods and storm categories. In the upper $20 \mathrm{~m}$, typical SD values are around $0.4^{\circ} \mathrm{C}$. From 20 to $200 \mathrm{~m}$, we find larger SD values between $\sim 0.6$ and $1.2^{\circ} \mathrm{C}$, and SD decreases below $200 \mathrm{~m}$. The background SDs for TS/TD locations show larger values below the surface $(20-200 \mathrm{~m})$ than for hurricane locations. However, none of these figures shows a systematical distribution of SDs across the storm track, thus suggesting again no substantial background biases. We detect a slight bias along the left side of the storm tracks within background SD for both TS/TD and hurricane locations, which may be due in part to the presence of more coastal pairs on the left side of TC tracks in high-activity TC regions.

These tests of the background variability show that background errors are generally small at all depths considered here (between 0 and $2000 \mathrm{~m}$ ) and timescales (between $0 \sim 20$ days) compared to the TC signals (discussed in the following sections), and we find no significant background biases using the footprint strategy. We will use these results as the basis (i.e., null hypothesis) for testing the significance of the observed TC effects in the following section.

\section{Appendix C: Null-hypothesis test on Argo data}

Here we present a null-hypothesis test to analyze whether the proposed footprint method is capable of capturing the tropical cyclone signals compared to the background variability. Our hypothesis is that the detected TC signals are significant compared to background noise. The null hypothesis is that the TC-induced signal is the average of background noise ( $H_{0}: \mu=B$, where $B$ is the mean of background noise). The alternative hypothesis claims TC-induced signals are either higher or lower than the average of the background noise $\left(H_{1}: \mu \neq B\right)$.

A two-sided $z$ test is conducted to test the hypothesis. Sampling distributions of the means (SDM) are used to assist in analyzing the results. Assuming the null hypothesis is true, the sampling distribution of TC-induced signals (denoted as " $x$ ") based on sample counts (denoted as " $n$ ") will be normally distributed with a mean of background mean (B) and standard error of $(\sigma / \sqrt{n})$, where $\sigma$ is the SD of background noise. Therefore, under hypothesis $H_{0}$, the observed " $x$ " should be $x-N(u, \sigma / \sqrt{n})$. We want to find an interval $\left(x^{-}, x^{+}\right)$for $\mathrm{x}$, which would lead to the acceptance of the null hypothesis. To meet this need, we calculate $x^{+}=z_{\text {stat }} \times \mathrm{SE}+B$ and $x^{-}=-z_{\text {stat }} \times \mathrm{SE}+\mathrm{B}$, where $z_{\text {stat }}$ 
quantifies how far $x$ is from $B$ in SD units. Here the value of $z_{\text {stat }}$ corresponds to a probability threshold (or $p$ value) of 0.05 . The value of 0.05 means the observed signals is "highly significant" within the $95 \%$ confidence interval, if they are outside the interval of $\left(x^{-}, x^{+}\right)$. SE is the standard error $(\sigma / \sqrt{n})$.

Based on this strategy, we calculate the "highly significant" intervals for temperature anomalies as a function of depth and distance, respectively (shades in Figs. 3 and 11), and for the footprint (thick solid contours in Figs. 2 and 10). In brief, the confidence interval in Figs. 2 and 10 is calculated by $x^{+}=z_{\text {stat }} \times \mathrm{SE}+B$ and $x^{-}=-z_{\text {stat }} \times \mathrm{SE}+B$ at each grid box. $\sigma$ is the $\mathrm{SD}$ of background noise calculated in Fig. B5, and the background mean $(B)$ is shown in Fig. B4. Sample counts $\mathrm{n}$ is the number of TC pairs at each grid box.

To obtain confidence intervals for Figs. 3 and 11, the mean $(B)$ and SD $(\sigma)$ of background noise with time and depth are calculated as in Fig. B2. While those for distance are set manually based on the notion that the background noise is confirmed to be white noise, the background mean with distance is set to zero, and the SD is set to the mean of SDs at the first 3 days.

\section{Appendix D: Test on the horizontal distances of the two Argo floats in a pair}

In this study, $0.2^{\circ}$ is selected as the maximum horizontal distance between the reference Argo and TC-affected Argo, since evidence suggests this choice will minimize the influences of the strong background signals (such as mesoscale eddies, strong Kuroshio, California currents, and internal waves). Ideally our footprint strategy aims to detect the ocean thermal changes at a fixed position. But, to obtain a satisfied number of pairs, the $0.2^{\circ}$ criterion is used; thus, there is the potential for sampling biases associated with horizontal and vertical motions on upper ocean currents. Therefore, it is necessary to test whether the selection of pairs within $0.2^{\circ}$ influences our main results.

Here we compare the position of floats before and after storms from each TC-affected pair by using two coordinate systems. This test is conducted for same-float pairs (i.e., the two profiles in a pair are both measured by the same float) and different-float pairs separately (i.e., the two profiles in a pair are measured by two different floats). One test uses latitude-longitude (Fig. D1a), and the other test uses track coordinates (Fig. D1b), and both coordinate systems use the location of the float before the storm as the origin. The post-storm float position appears to be randomly distributed around the initial pre-storm position. We examine the drifting direction along and across the track at different distances from the float to the track center, where the distance between pre-storm and post-storm Argo is calculated in track coordinates. Figure D2 shows that floats drift moderately but systematically in the water under forces of TCs,
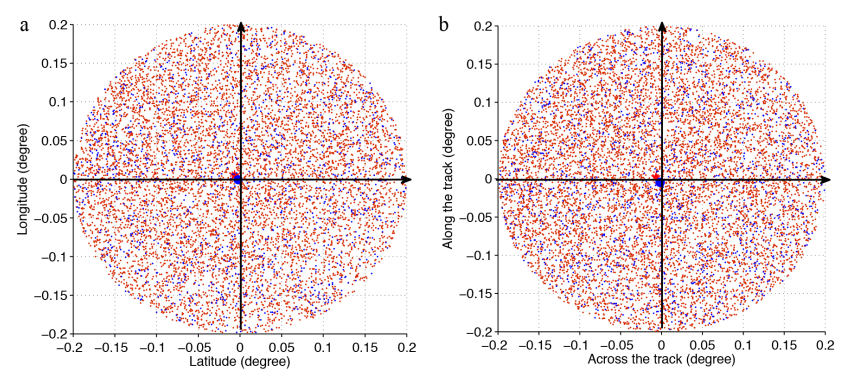

Figure D1. Schematic scatter plots showing Argo floats' drifting destination from the origin. The two coordinate systems are (a) latitude-longitude, with the location of the float before storm as the origin, and (b) track direction as the $y$ axis, and the location of the float before the storm as the origin. The red dots are the destination of the pairs with pairs from the same float in red (with the mean in red star) and pairs from different floats in blue (with the mean in big blue dot).

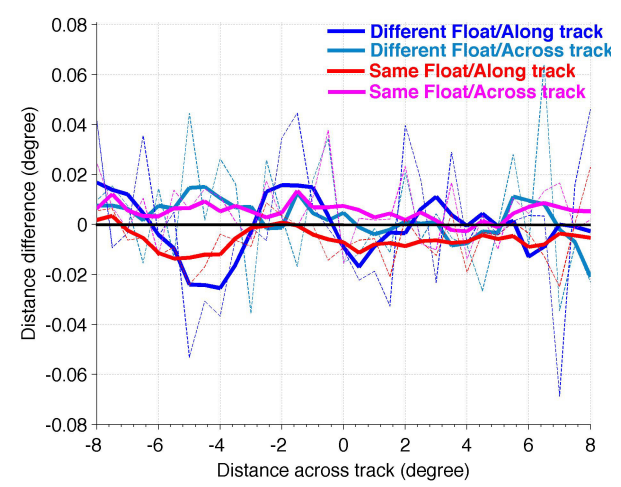

Figure D2. Horizontal distance difference between the two profiles in a TC-affected pair along and across the track as a function of the distance from the float location to the track center (dashed curves). Here the distance is calculated in track coordinates; i.e., a positive distance across the track represents the inertial-resonant side (right side in the Northern Hemisphere and left side in the Southern Hemisphere). The horizontal distances by using pairs where the two profiles are from different floats are shown in dark blue (along track) and light blue (across track), while drifting distances based on the remaining pairs are shown in purple (across track) and red (along track). The values are further smoothed using a five-point $\left(2.5^{\circ}\right)$ moving filter (solid curves).

and a float tends to move away from the storm track (pink) and move backward along the storm track (red). However, we cannot explain these movements using the current methods, due to dynamical effects such as surface wind forcing, nearinertial currents, and mean currents at Argo parking depths. But, we find no systematical drift distance for different-float pairs. Since the maximum systematical drift within 20 days is less than $5 \mathrm{~km}$, this distance is relatively small compared to the maximum displacement distance of $20 \mathrm{~km}$. Therefore, we assume horizontal motions of the floats do not affect our 
essential results. Approximately, $17 \%$ of pairs used in our analysis are considered different-float pairs.

Furthermore, it is worth noting that Argo profiles affected by TCs may potentially be labeled as poor-quality data in the delayed mode quality control process (Yu et al., 2010), since data are typically rejected if there are dramatic changes in temperature or salinity profiles. In this study, we include the real-time Argo profiles as well as the delayed-mode data.

However, we do not attempt to recover wrongly labeled data. 
Acknowledgements. This work is supported by the "Structures, Variability and Climatic Impacts of Ocean Circulation and Warm Pool in the Tropical Pacific Ocean" project of the National Basic Research Program of China (grant no. 2012CB417404) and Chinese Academy of Sciences' project "Western Pacific Ocean System: Structure, Dynamics and Consequences" (grant no. XDA11010405).

Edited by: M. Hecht

\section{References}

Ascani, F., Firing, E., Dutrieux, P., McCreary, J. P., and Ishida, A.: Deep equatorial ocean circulation induced by a forced-dissipated Yanai beam, J. Phys. Oceanogr., 40, 1118-1142, 2010.

Bell, M. M., Montgomery, M. T., and Emanuel, K. A.: Air-sea enthalpy and momentum exchange at major hurricane wind speeds observed during CBLAST, J. Atmos. Sci., 69, 3197-3222, doi:10.1175/jas-d-11-0276.1, 2012.

Bender, M. A., Knutson, T. R., Tuleya, R. E., Sirutis, J. J., Vecchi, G. A., Garner, S. T., and Held, I. M.: Modeled impact of anthropogenic warming on the frequency of intense Atlantic hurricanes, Science, 327, 454-458, doi:10.1126/science.1180568, 2010.

Black, W. J. and Dickey, T. D.: Observations and analyses of upper ocean responses to tropical storms and hurricanes in the vicinity of Bermuda, J. Geophys. Res.-Oceans, 113, C08009, doi:10.1029/2007JC004358, 2008.

Braun, S. A.: High-resolution simulation of Hurricane Bonnie, 1998. Part II: Water budget, J. Atmos. Sci., 63, 43-64, 2006.

Brink, K. H.: Observations of the response of thermocline currents to a hurricane, J. Phys. Oceanogr., 19, 1017-1022, 1989.

Camargo, S. J. and Sobel, A. H.: Western North Pacific tropical cyclone intensity and ENSO, J. Climate, 18, 2996-3006, 2005.

Chan, J. C. and Kepert, J. D.: Global Perspectives on Tropical Cyclones: from Science to Mitigation, Vol. 4, World Scientific Publishing Company, 94., 2010.

Cione, J. J. and Uhlhorn, E. W.: Sea surface temperature variability in hurricanes: implications with respect to intensity change, Mon. Weather Rev., 131, 1783-1796, 2003.

Dare, R. A. and McBride, J. L.: Sea surface temperature response to tropical cyclones, Mon. Weather Rev., 139, 3798-3808, 2011.

D'Asaro, E. A.: The ocean boundary layer below Hurricane Dennis, J. Phys. Oceanogr., 33, 561-579, 2003.

Deal, R.: Surface heating and restratification of the ocean after a tropical cyclone, Electronic Theses, Treatises and Dissertations, Paper 60, 2011.

Dickey, T., Frye, D., McNeil, J., Manov, D., Nelson, N., Sigurdson, D., Jannasch, H., Siegel, D., Michaels, T., and Johnson, R.: Upper-Ocean Temperature Response to Hurricane Felix as Measured by the Bermuda Testbed Mooring, Mon. Weather Rev., 126, 1195-1201, 1998.

Emanuel, K.: Contribution of tropical cyclones to meridional heat transport by the oceans, J. Geophys. Res.-Atmos., 106, 1477114781, 2001.

Emanuel, K.: Environmental factors affecting tropical cyclone power dissipation, J. Climate, 20, 5497-5509, doi:10.1175/2007jcli1571.1, 2007.
Emanuel, K. A.: The theory of hurricanes, Annu. Rev. Fluid Mech., 23, 179-196, 1991.

Emanuel, K. A.: Thermodynamic control of hurricane intensity, Nature, 401, 665-669, 1999.

Fedorov, A. V., Brierley, C. M., and Emanuel, K.: Tropical cyclones and permanent El Nino in the early Pliocene epoch, Nature, 463, 1066-1084, 2010.

Freeland, H., Roemmich, D., Garzoli, S., LeTraon, P., Ravichandran, M., Riser, S., Thierry, V., Wijffels, S., Belbéoch, M., Gould, J., Grant, F., Ignazewski, M., King, B., Klein, B., Mork, K., Owens, B., Pouliquen, S., Sterl, A., Suga, T., Suk, M., Sutton, P., Troisi, A., Vélez-Belchi, P., and Xu, J.: Argo a decade of progress, in: Proceedings of OceanObs'09: Sustained Ocean Observations and Information for Society Venice, Italy, 21-25 September 2009, edited by: Hall, J., Harrison, D. E., and Stammer, D., ESA Publication WPP-306, 2009.

Geisler, J. E.: Linear theory of the response of a two layer ocean to a moving hurricane, Geophys. Astro. Fluid, 1, 249-272, 1970.

Ginis, I.: Tropical cyclone-ocean interactions. Atmosphere-ocean interactions, edited by: Perrie, W., Adv. Fluid Mech. Ser., 33, 83-114, 2002.

Hart, R. E.: An inverse relationship between aggregate Northern Hemisphere tropical cyclone activity and subsequent winter climate, Geophys. Res. Lett., 38, L01705, doi:10.1029/2010GL045612, 2011.

Hart, R. E., Bosart, L. F., and Hosler, C.: The possible seasonal climate impact from anomalous frequency of recurving tropical cyclones, in: Preprints, 19th Conf. on Climate Variability and Change, San Antonio, TX, USA, Amer. Meteor. Soc., 6.3, 2007a.

Hart, R. E., Maue, R. N., and Watson, M. C.: Estimating local memory of tropical cyclones through MPI anomaly evolution, Mon. Weather Rev., 135, 3990-4005, 2007b.

Huang, P., Sanford T. B., and Imberger, J.: Heat and turbulent kinetic energy budgets for surface layer cooling induced by the passage of Hurricane Frances (2004), J. Geophys. Res., 114, C12023, doi:10.1029/2009JC005603, 2009.

Jacob, S. D. and Shay, L. K.: The role of oceanic mesoscale features on the tropical cyclone-induced mixed layer response: a case study, J. Phys. Oceanogr., 33, 649-676, 2003.

Jaimes, B. and Shay, L. K.: Near-inertial wave wake of hurricanes Katrina and Rita over mesoscale oceanic eddies, J. Phys. Oceanogr., 40, 1320-1337, 2010.

James, B., Shay, L. K., and Halliwell, G. R.: The response of quasigeostrophic oceanic vortices to tropical cyclone forcing, J. Phys. Oceanogr., 41, 1965-1985, 2011.

Jansen, M. F., Ferrari, R., and Mooring, T. A.: Seasonal vs. permanent thermocline warming by tropical cyclones, Geophys. Res. Lett., 37, L03602, doi:10.1029/2009GL041808, 2010.

Josey, S. A., Kent, E. C., and Taylor, P. K.: New insights into the ocean heat budget closure problem from analysis of the SOC airsea flux climatology, J. Climate, 12, 2856-2880, 1999.

Kalnay, E., Kanamitsu, M., Kistler, R., Collins, W., Deaven, D., Gandin, L., Iredell, M., Saha, S., White, G., Woollen, J., Zhu, Y., Leetmaa, A., Reynolds, R., Chelliah, M., Ebisuzaki, W., Higgins, W., Janowiak, J., Mo, K. C., Ropelewski, C., Wang, J., Jenne, R., and Joseph, D.: The NCEP/NCAR 40-Year Reanalysis Project. B. Am. Meteorol. Soc., 77, 437-471, 1996.

Knutson, T. R., McBride J. L., Chan J., Emanuel K., Holland G., Landsea C., Held I., Kossin J. P., Srivastava A. K., and Sugi M.: 
Tropical cyclones and climate change, Nat. Geosci., 3, 157-163, 2010.

Levitus, S., Antonov, J. I., Boyer, T. P., Baranova, O. K., Garcia, H. E., Locarnini, R. A., Mishonov, A. V., Reagan, J. R., Seidov, D., Yarosh, E. S., and Zweng, M. M.: World ocean heat content and thermosteric sea level change, 0-2000 m: 1955-2010, Geophys. Res. Lett., 39, L10603, doi:10.1029/2012GL051106, 2012.

Lin, I. I., Pun, I. F., and Wu, C. C.: Upper-ocean thermal structure and the western North Pacific category 5 typhoons. Part II: Dependence on translation speed, Mon. Weather Rev., 137, 3744 3757, 2009a.

Lin, I. I., Chen, C. H., Pun, I. F., Liu, W. T., and Wu, C. C.: Warm ocean anomaly, air sea fluxes, and the rapid intensification of tropical cyclone Nargis (2008), Geophys. Res. Lett., 36, L03817, doi:10.1029/2008GL035815, 2009b.

Liu, Z., Xu, J., Zhu, B., Sun, C., and Zhang, L.: The upper ocean response to tropical cyclones in the northwestern Pacific analyzed with Argo data, Chin. J. Oceanogr. Limnol., 25, 123-131, 2007.

Lloyd, I. D. and Vecchi, G. A.: Submonthly Indian Ocean cooling events and their interaction with large-scale conditions, J. Climate, 23, 700-716, 2010.

Lloyd, I. D. and Vecchi, G. A.: Observational evidence for oceanic controls on hurricane intensity, J. Climate, 24, 1138-1153, 2011.

Mcphaden, J. M., Foltz, G. R., Lee, T., Murty, V. S. N., Ravichandran, M., Vecchi, G. A., Vialard, J., Wiggert, J. D., and Yu, L.: Ocean-atmosphere interactions during cyclone Nargis, EOS T. Am. Geophys. Un., 90, 53-54, doi:10.1029/2009EO070001, 2009.

Mei, W. and Pasquero, C.: Spatial and temporal characterization of sea surface temperature response to tropical cyclones, J. Climate, 26, 3745-3765, 2013.

Mei, W., Primeau, F., McWilliams, J. C., and Pasquero, C.: Sea surface height evidence for long-term warming effects of tropical cyclones on the ocean, P. Natl. Acad. Sci. USA, 110, 1520715210, 2013.

Park, J. J., Kwon, Y. O., and Price, J. F.: Argo array observation of ocean heat content changes induced by tropical cyclones in the north Pacific, J. Geophys. Res., 116, C12025, doi:10.1029/2011JC007165, 2011.

Powell, M. D., Vickery, P. J., and Reinhold, T. A.: Reduced drag coefficient for high wind speeds in tropical cyclones, Nature, 422, 279-283, 2003.

Price, J. F.: Upper ocean response to a hurricane, J. Phys. Oceanogr., 11, 153-175, 1981.

Price, J. F.: Internal wave wake of a moving storm. 1. Scales, energy budget and observations, J. Phys. Oceanogr., 13, 949-965, 1983.

Price, J. F., Sanford, T. B., and Forristall, G. Z.: Forced stage response to a moving hurricane, J. Phys. Oceanogr., 24, 233-260, 1994.

Price, J. F., Morzel, J., and Niiler, P. P.: Warming of SST in the cool wake of a moving hurricane, J. Geophys. Res.-Oceans, 113, C07010, doi:10.1029/2007JC004393, 2008.
Sanford, T. B., Price, J. F., and Girton, J. B.: Upper-ocean response to hurricane Frances (2004) observed by profiling EM-APEX floats, J. Phys. Oceanogr., 41, 1041-1056, 2011.

Shay, L. K. and Elsberry, R. L.: Near-inertial ocean current response to hurricane Frederic, J. Phys. Oceanogr., 17, 1249-1269, 1987.

Shay, L. K., Elsberry, R. L., and Black, P. G.: Vertical structure of the ocean current response to a hurricane, J. Phys. Oceanogr., 19, 649-669, 1989.

Shay, L. K., Mariano, A. J., Jacob, S. D., and Ryan, E. H.: Mean and near-inertial ocean current response to hurricane Gilbert, J. Phys. Oceanogr., 28, 858-889, 1998.

Smith, S. R., Hughes, P. J., and Bourassa, M. A.: A comparison of nine monthly air-sea flux products, Int. J. Climatol., 31, 10021027, doi:10.1002/joc.2225, 2011.

Sriver, R. L. and Huber, M.: Observational evidence for an ocean heat pump induced by tropical cyclones, Nature, 447, 577-580, 2007.

Sriver, R. L. and Huber, M.: Modeled sensitivity of upper thermocline properties to tropical cyclone winds and possible feedbacks on the Hadley circulation, Geophys. Res. Lett., 37, L08704, doi:10.1029/2010GL042836, 2010. Sriver, R. L., Huber M., and Nusbaumer J.: Investigating tropical cycloneclimate feedbacks using the TRMM Microwave Imager and the Quick Scatterometer, Geochem. Geophy. Geosy., 9, Q09V11, doi:10.1029/2007gc001842, 2008.

Sriver, R. L., Goes, M., Mann, M. E., and Keller, K.: Climate response to tropical cyclone-induced ocean mixing in an Earth system model of intermediate complexity, J. Geophys. Res.-Oceans, 115, C10042, doi:10.1029/2010JC006106, 2010.

Sriver, R. L., Huber, M., and Chafik, L.: Excitation of equatorial Kelvin and Yanai waves by tropical cyclones in an ocean general circulation model, Earth Syst. Dynam., 4, 1-10, doi:10.5194/esd4-1-2013, 2013.

Trenberth, K. E., Davis, C. A., and Fasullo, J.: Water and energy budgets of hurricanes: Case studies of Ivan and Katrina, J. Geophys. Res.-Atmos., 112, D23107, 2007.

Trenberth, K. E., Fasullo, J. T., and Kiehl, J.: Earth's global energy budget, B. Am. Meteorol. Soc., 90, 311-323, 2009.

von Schuckmann, K. and Le Traon, P. Y.: How well can we derive Global Ocean Indicators from Argo data?, Ocean Sci., 783-791, 2011.

Willis, J. K., Lyman, J. M., Johnson, G. C., and Gilson, J.: In Situ Data Biases and Recent Ocean Heat Content Variability, J. Atmos. Ocean. Tech., 26, 846-852, 2009.

Wright, C. W., Walsh, E. J., Vandemark, D., Krabill, W. B., Garcia, A. W., Houston, S. H., Powell, M. D., Black, P. G., and Marks, F. D.: Hurricane directional wave spectrum spatial variation in the open ocean, J. Phys. Oceanogr., 31, 2472-2488, 2001.

Yu, T., Han, G. J., Guan, C. L., and Deng, Z. G.: Several important issues in salinity quality control of Argo float, Mar. Geod., 33, 424-436, 2010. 